Revista Brasileira de Meteorologia, v.28, n.1, 105 - 121, 2013

\title{
VALIDAÇÃO DE POLUENTES FOTOQUÍMICOS E INCLUSÃO DO INVENTÁRIO DE EMISSÕES NO MODELO DE QUALIDADE DO AR WRF/CHEM, PARA A REGIÃO METROPOLITANA DE SÃO PAULO
}

\author{
ROSIBERTO SALUSTIANO DA SILVA JUNIOR ${ }^{1}$, MARIA DE FÁTIMA ANDRADE² \\ ${ }^{1}$ Universidade Federal de Alagoas, Instituto de Ciências Atmosféricas (UFAL/ICAT), Maceió, AL, Brasil \\ ${ }^{2}$ Universidade de São Paulo, Instituto de Astronomia, Geofísica e Ciências Atmosféricas (USP/IAG), São Paulo, SP, \\ Brasil \\ rosiberto@icat.ufal.br, mftandra@model.iag.usp.br
}

Recebido Março de 2011 - Aceito julho de 2012

\begin{abstract}
RESUMO
Este trabalho mostra os resultados das aproximações feitas para o inventário de emissões de poluentes da Região Metropolitana de São Paulo (RMSP) e transformações necessárias para serem implementadas no modelo fotoquímico WRF/CHEM ("Weather Research and Forecasting / CHEMistry"). Portanto, o objetivo é avaliar a eficiência do modelo WRF/CHEM em simular os poluentes fotoquímicos para a RMSP, utilizando as concentrações de monóxido de carbono $(\mathrm{CO})$ e ozônio troposférico $\left(\mathrm{O}_{3}\right)$. $\mathrm{O}$ WRF/Chem é um modelo de previsão de tempo, clima e qualidade do ar, que resolve em conjunto e de forma simultânea os modulos de meteorologia e química. A RMSP é considerada uma das dez maiores metropoles do mundo, e sofre igualmente a outros centros urbanos com o problema da poluição atmosférica. Pesquisas realizadas na RMSP mostram que os automóveis são as principais fontes de $\mathrm{CO}$, hidrocarbonetos totais (HC) e Óxidos Nitrogenados (NOx). Para Óxidos de Enxofre (SOx), as indústrias e os automóveis são fontes importantes na emissão de SOx e emissão de partículas inaláveis (PM10). Outro fator muito importante é a ressuspensão de partículas do solo e formação de aerossóis secundários. Para estimar as emissões será usado o estudo do inventário feito pela Companhia Ambiental do Estado de São Paulo (CETESB) para o ano de 2006, onde estas informações serão trabalhadas para adequação ao formato de entrada do modelo $\mathrm{WRF} / \mathrm{Chem}$, pois esse levantamento anual de emissãos de poluentes é feito para toda a RMSP. Logo, algumas das propostas foram de gerar aproximações para tornar as emissões mais representativas, em termos de distribuição espacial e temporal. Os resultados mostraram que tais aproximações melhoram a previsão da concentração de ozônio $\left(\mathrm{O}_{3}\right)$ e de $\mathrm{CO}$ em cerca de $25 \%$, atingindo coeficientes de correlação de 0,79 para ozônio e 0,49 para monóxido de carbono, quando comparado os dados simulados e observados.
\end{abstract}

Palavras-Chave: Poluição do Ar, Emissões, Modelos de Qualidade do Ar.

ABSTRACT: PREDICTION OF PHOTOCHEMICAL POLLUTANTS IN METROPOLITAN
AREA OF SÃO PAULO USING AIR QUALITY MODEL (WRF/CHEM) AND THE CETESP
POLLUTANTS EMMISSION INVENTORY
This paper shows the results of an approximation and transformation made on the Sao Paulo
Metropolitan Region (SPMR) pollutant emission inventory, required to be used as input data on
the WRF/Chem model ("Weather Research This paper shows the results of an approximation and
transformation made on the Sao Paulo Metropolitan Region (SPMR) pollutant emission inventory,
required to be used as input data on the WRF/Chem model ("Weather Research and Forecasting /
CHEMistry"). Therefore, the purpose is to evaluate the efficiency of the WRF/Chem model to simulate
photochemical pollutants on the SPMR, using as parameters the inclusion of the emission inventory and
measurements of carbon monoxide (CO) and tropospheric ozone $\left(\mathrm{O}_{3}\right)$ concentrations. The WRF/Chem
is a forecast, weather climate and air quality model, which solves simultaneously the meteorology
and chemistry modules. SPMR is considered one of the largest cities in the world, and like other big
cities suffer with atmospheric pollution. Researches made in SPMR show that vehicles are the main 
sources of Carbon monoxide (CO), Hydrocarbon (HC) and Nitrogen oxide (NOx). When it comes to Sulphur oxides (SOx) and inhalable particles (PM10) the main sources of emission fundamentally are industries and vehicles. Another crucial factor is the resuspension of particles from the ground (soil) and the formation of secondary aerosols. A 2006 Companhia Ambiental do Estado de São Paulo (CETESB) inventory of emissions will be used as input data to the WRF/CHEM model. Since the annual CETESB inventory of emissions integrates the whole SPMR some approximation is required to match the model input data format. It was proposed some approximation methods in which the inventory of annual emissions was representatively distributed in time and space as required by the model. The results show that these methods improved the forecasting of the ozone $\left(\mathrm{O}_{3}\right)$ and of $\mathrm{CO}$ concentration by approximately $25 \%$, reaching a correlation coefficients of $0,79 \%$ for the ozone and $0,49 \%$ for carbon monoxide, when comparing simulations and observations.

Keywords: Air Pollution, Emissions, Air Quality Models.

\section{INTRODUÇÃO}

A poluição do ar tem sido, desde a primeira metade do século XX, um grave problema nos centros urbanos industrializados, com a presença cada vez maior dos automóveis, que vieram a somar com as indústrias, como fontes poluidoras. Episódios de poluição excessiva causaram aumento do número de mortes em algumas cidades da Europa e Estados Unidos. O primeiro episódio ocorreu em 1930, no vale de Meuse, Bélgica, entre as cidades de Huy e Liége, uma região com grande concentração de indústrias, distribuídas em uma faixa de aproximadamente vinte quilômetros de comprimento. Porém, o mais clássico e o mais grave dos episódios, acerca dos efeitos deletérios dos poluentes do ar, ocorreu em Londres. Durante o inverno de 1952, um episódio de inversão térmica impediu a dispersão de poluentes, gerados pelas indústrias e pelos aquecedores domiciliares que utilizavam carvão como combustível. Uma nuvem, composta principalmente por material particulado e enxofre (em concentrações até nove vezes maiores do que a média de ambos), se formou e permaneceu estacionada sobre a cidade por aproximadamente três dias, levando a um aumento de 4.000 mortes em relação à média de óbitos em períodos semelhantes (Braga, et. al. 2002).

A Região Metropolitana de São Paulo (RMSP) é considerada uma das dez maiores cidades do mundo, e como qualquer outro grande centro urbano, sofre com um dos maiores males do século XXI que é a poluição da atmosfera. De acordo com o estudo feito pela CETESB em 2005, os veículos automotores são as principais fontes de monóxido de carbono (CO), hidrocarbonetos totais (HC) e óxidos de nitrogênio (NOx). Para os óxidos de enxofre ( $\mathrm{SOx}$ ), as indústrias e os veículos são importantes fontes. As partículas inaláveis (PM10) recebem a contribuição de outros fatores, como a ressuspensão de partículas do solo e a formação de aerossóis secundários.

Devido às constantes ultrapassagens do padrão de qualidade do ar como no caso do ozônio, monóxido de carbono, material particulado entre outros, muitas pesquisas são dedicadas para avaliar e quantificar os efeitos da poluição atmosférica no sistema solo-planta-atmosfera, na tentativa de obter informações que possibilitem tomadas de decisões para diminuir os efeitos da poluição atmosférica sobre os seres vivos.

Como exemplo do efeito da poluição atmosférica sobre a saúde humana, a exposição prolongada de pessoas a alta concentração de ozônio pode ocasionar irritação nos olhos e nas vias respiratórias, além do agravamento de doenças respiratórias preexistentes, como a asma. Sabe-se que a exposição repetida ao ozônio pode tornar as pessoas mais suscetíveis a infecções respiratórias e inflamação nos pulmões. Adultos e crianças saudáveis também estão sujeitos aos efeitos danosos causados pelo ozônio se expostos a níveis elevados durante a prática de exercícios físicos. Além de danoso à saúde humana, o ozônio é prejudicial à vegetação, causando danos às colheitas e à vegetação natural. Os efeitos observados em plantas referem-se à diminuição na taxa de crescimento, aumento da vulnerabilidade a insetos e problemas de pigmentação devido a alterações no processo de fotossíntese (Saldiva, et al., 1995).

Este trabalho tem como objetivo principal avaliar a eficiência do modelo WRF/Chem em simular os poluentes fotoquímicos para a RMSP, utilizando como parâmetros a inclusão do inventário de emissões e medições das concentrações de $\mathrm{CO}$ e ozônio troposférico $\left(\mathrm{O}_{3}\right)$.

\section{METODOLOGIA}

\section{1 Área de estudo}

A Região Metropolitana de São Paulo (Figura 1) está localizada a $23^{\circ} \mathrm{S}$ e $46^{\circ} \mathrm{W}$, na porção sudeste do Brasil. Possui uma área de $8.051 \mathrm{~km}^{2}$ com uma população superior a 19 milhões de habitantes, distribuída em uma área urbanizada e de maneira desordenada em $1.747 \mathrm{~km}^{2}$ dessa área. O sítio urbano situa-se, praticamente, na Bacia Sedimentar de São Paulo, cujo principal vale é o do Rio Tietê, orientado no sentido Leste-Oeste, com uma altitude média de 720 metros e uma extensa planície de 
inundação (CETESB, 2005; Castanho, 2005; Silva Junior et al, 2009). Durante o inverno, formações de alta pressão no Oceano Atlântico ao Leste, dirigem-se para o Norte, produzindo ventos fracos provenientes da costa, fortes inversões térmicas de subsidência e céu claro. Sua precipitação anual é de 1900 $\mathrm{mm}$, com temperatura média que varia entre $15-22^{\circ} \mathrm{C}$ (CETESB, 2005; Castanho, 1999).

\subsection{Descrição das simulações e do período estudado}

As previsões serão feitas utilizando o modelo WRF/Chem versão 2.1 (Weather Research and Forecasting/Chemistry), que é um modelo não-hidrostático de previsão numérica do tempo desenvolvido pelo NCAR (National Center for Atmospheric Research) com colaboração de diversas universidades e outros institutos de pesquisas (Skamarock et al., 2005). O WRF/ Chem foi configurado para fazer simulação com duração de 96 horas, durante o período de 28/10/2006 00UTC até 01/11/2006 00UTC, este período de estudo foi escolhido de acordo com a disponibilidade dos dados para validação, por se tratar de meses com maiores índices de concentração de ozônio, e ainda pelo fato de ter apresentado grandes variações meteorológicas e da química da atmosfera, devido principalmente à situação sinótica. O domínio horizontal possui $60 \times 30$ pontos com espaçamento de $5 \mathrm{~km}$ centrado em $46,65^{\circ} \mathrm{W}$ e $23,62^{\circ} \mathrm{S}$ (o domínio é mostrado na Figura 2). Na vertical foram usados 31 níveis com o topo do modelo em $50 \mathrm{hPa}$. As opções de parametrizações utilizadas na simulação estão sendo apresentadas na Tabela 1.

Foram utilizados os dados do modelo global do National Centers for Environmental Prediction (NCEP), representados pelo modelo global operacional Global Forecast System - Final (GFS-FNL) com dados de análises de resolução espacial 1,0 x 1,0 graus e temporal a cada 6 horas, como condições iniciais e de fronteira para o modelo WRF, que estão disponíveis no

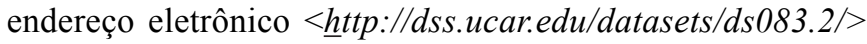
a partir de 1999. Os dados iniciais para a química foram baseados no inventário de emissões feito pela CETESB para a RMSP ano base 2006, e ainda dados obtidos de especiação de hidrocarbonetos e fatores de emissão de experimentos realizados pelo laboratório LAPAt IAG/USP (Andrade et al., 2004, Martins, 2006 e Sanchez-Ccoyllo et al., 2006). As simulações foram validadas utilizando as medições realizadas

Tabela 1 - Configuração do Modelo para a Simulação.

\begin{tabular}{l|l}
\hline Física do Modelo & \multicolumn{1}{c}{ Parametrizações Utilizadas } \\
\hline Microfísica da Atmosfera & Purdue Lin (Lin et al., 1983) \\
\hline Radiação de Onda Longa & RRTM scheme \\
\hline Radiação de Onda Curta & Dudhia scheme (Dudhia, 1989) \\
\hline Camada Limite Superficial & Monin-Obukhov (Janjic ETA) scheme \\
\hline Superfície Terrestre & NOAH Land-Surface Model \\
\hline Camada Limite Atmosférica & Mellor-Yamada-Janjic scheme (MYJ) \\
\hline Parametrização de Cumulus & Grell-Devenyi Ensemble scheme \\
\hline Esquema de fotólises & Madronich (1987) \\
\hline Módulo Químico & RADM2 \\
\hline Módulo de Aerossóis & MADE/SORGAM \\
\hline
\end{tabular}

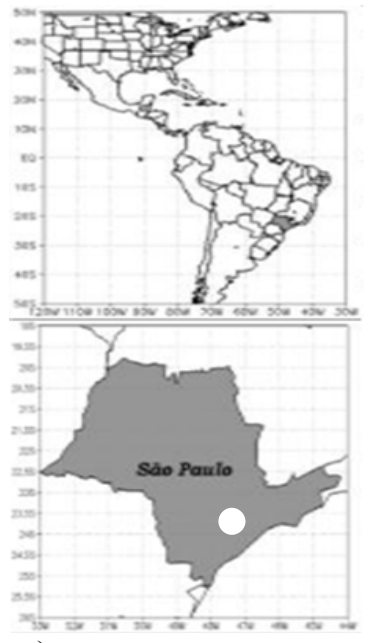

a)

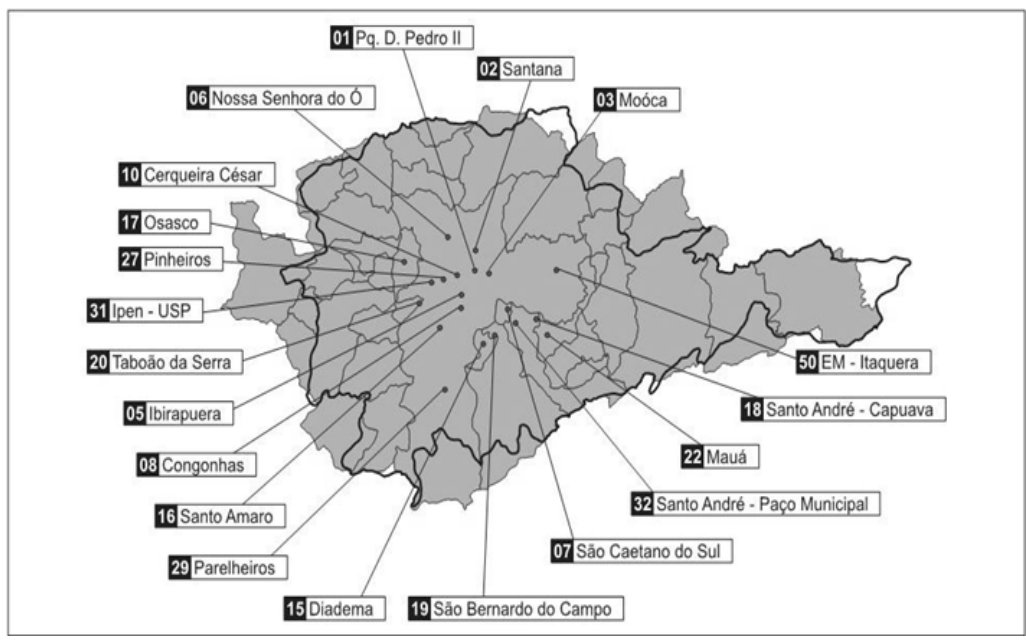

b)

Figura 1- (a) Localização da área de estudo na América do Sul e Brasil e (b) RMSP e a localização das estações de monitoramento da CETESB. Fonte: CETESB, 2012 
durante os meses de outubro e novembro de 2006 (experimento de Politicas Públicas), no qual foram lançadas radiosondagens e ozoniosondas para obter o perfil vertical da velocidade do vento, temperatura do ar, e pressão parcial de ozônio (depois convertida para concentração de ozônio).

\subsection{Descrição da parte química do modelo WRF/Chem}

Os modelos fotoquímicos, como no caso do WRF/ Chem, resolvem a equação da dispersão dos contaminantes atmosféricos representando os fenômenos físicos e as reações fotoquímicas, que afetam as espécies químicas presentes na atmosfera e que condicionam a distribuição espacial e temporal de suas concentrações. Já a parte da meteorologia do modelo amplamente testada foi originada da quinta geração do modelo MM5 (Mesoscale Model version 5, Grell et al., 2000), no sentido de aproveitar as experiências e conhecimentos adquiridos para a construção e desenvolvimento do modelo climático WRF, que ganhou uma nova versão com a inclusão da química, gerando o WRF/Chem.

O módulo químico consiste no tratamento das emissões antropogênicas e biogênicas, onde são incluídos os efeitos da deposição seca dos constituintes gasosos e particulados, cálculo de taxas de fotólise, e um módulo de aerossóis para formação e crescimento. O WRF/Chem é um modelo estatisticamente avaliado e comparado a outros, como por exemplo no estudo feito por Grell et al. (2005) que compararam os modelos WRF/ Chem e MM5/Chem, onde os resultados mostraram uma melhor eficiência na previsão do $\mathrm{O}_{3}$ em favor do modelo WRF/ Chem. Vale salientar que o modulo de tratamento de aerossóis foi desligado por falta de informações sobre o inventário de emissões dos aerossóis para a área de estudo, e ainda pelo fato de que a concentração dos aerossóis não ser o foco do presente trabalho.

\subsubsection{Emissões Antropogênicas}

Foi utilizado o inventário oficial de emissões elaborado pela CETESB para o ano de 2006 (CETESB, 2006). Nesses inventários as emissões veiculares (fontes móveis) foram responsáveis pela maior parte das emissões gasosas na RMSP. De acordo com esse relatório CETESB (ano base 2006) a emissão das fontes móveis são responsáveis por aproximadamente 97\% das emissões de CO (monóxido de carbono), 97\% das emissões de HC (hidrocarbonetos totais), 96\% das emissões de NOx (óxidos nitrogenados), $40 \%$ das emissões de material particulado e $35 \%$ das emissões de SOx (óxidos de enxofre). Neste estudo somente as fontes móveis foram consideradas, para a emissões de Monóxido de Carbono $\left(\mathrm{CO}=1478,8 \times 10^{3} \mathrm{t} /\right.$ ano), Hidrocarbonetos Totais $\left(\mathrm{HC}=358,1 \times 10^{3} \mathrm{t} / \mathrm{ano}\right)$, Óxidos de Nitrogênio (NOx=330,9x10 $0^{3}$ ton/ano), Óxidos de Enxofre ( $\mathrm{SOx}=9,1 \times 10^{3} \mathrm{t} / \mathrm{ano}$ ), e Material Particulado (MP $=19,8 \times 10^{3} \mathrm{t} /$ ano). A estimativa para toda a RMSP (baseado em CETESB, 2006), considera a emissão do escapamento (exaustão), cárter e evaporativo (líquido) e transferência de combustível (vapor), para gasolina tipo C com $22 \%$ de álcool, álcool e Diesel com $300 \mathrm{ppm}$ de enxofre (massa).

A unidade e o formato do inventário de emissões da CETESB foram alterados para atender o módulo de assimilação dos dados de emissão do modelo WRF/Chem, onde foram feitas conversões de unidade de t/ano (CETESB) para $\mu$.mol. $\mathrm{km}^{-2} \cdot \mathrm{h}^{-1}$ (WRF/Chem). A classificação dos compostos orgânicos voláteis (COV) foi feita de acordo com o método SAPRAC99 (maiores detalhes em Carter, 2000). O SAPRAC99 agrupa várias espécies de compostos orgânicos voláteis de acordo com as taxas de velocidade de reação e peso molecular, totalizando 30 constituintes químicos de entrada (e_so2, e_no, e_ald, e_hcho, e_ora2, e_nh3, e_hc3, e_hc5, e_hc8, e_eth, e_co, e_ol2, e_olt, e oli, e_tol, e_xyl, e_ket, e_csl, e_iso, e_pm25i, e_pm25j, e_so4i, e_so4j, e_no3i, e_no3j, e_orgi, e_orgj, e_eci, e_ecj, e_pm10).

Como o inventário oficial de emissões da CETESB foi feito para toda a RMSP, ou seja, sem considerar as variações temporais e espaciais, logo foi necessário diferenciar a quantidade de emissão de acordo com áreas de muito/pouco tráfego de veículos, e ainda incorporar o efeito da variação horária das emissões. Essas aproximações foram feitas no sentido de melhorar a representatividade do inventário de emissões.

Para a representação espacial do inventário de emissões da CETESB (em termos de fluxo de poluentes por ponto de grade) foi utilizado o estudo desenvolvido por Landmman (2004) para a RMSP. Nesse estudo, um modelo de tráfego EMME/2, gera para cada ponto de grade a velocidade média por tipo de veículo, leve ou pesado. A partir dessa velocidade média foi calculada uma taxa de emissão por poluente relativa ao inventário oficial. A distribuição espacial da emissão fica descrita com base na quantidade de veículos e na velocidade média por trama para a RMSP (na Figura 2a, os tons de cinza expressa a quantidade de emissão de $\mathrm{CO}$, relacionada ao fluxo de veículos na área em questão).

Para implementar a distribuição espacial das emissões veiculares foram estipulados pesos com base na Figura 2a, levando em consideração a contribuição relativa dos pontos de grade do modelo (células com resolução de $5 \mathrm{~km} \times 5 \mathrm{~km}$ ) para toda emissão referente a área da RMSP $\left(1.747 \mathrm{Km}^{2}\right)$, ou seja, o percentual da emissão total da RMSP é dividida pelas células com mesmo fluxo de veículos. Foram criadas classes de emissão baseadas no perfil de emissões de CO (mostrado na Figura 2a que o CO seria um indicador de trânsito de veículos leves) para determinar quais seriam as regiões com maiores contribuições 


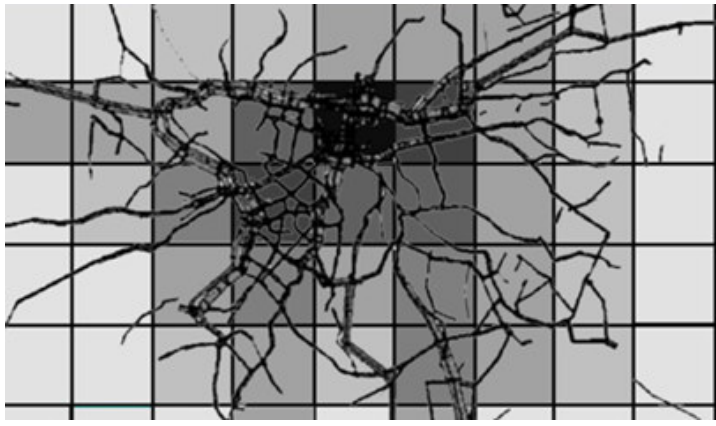

(a)

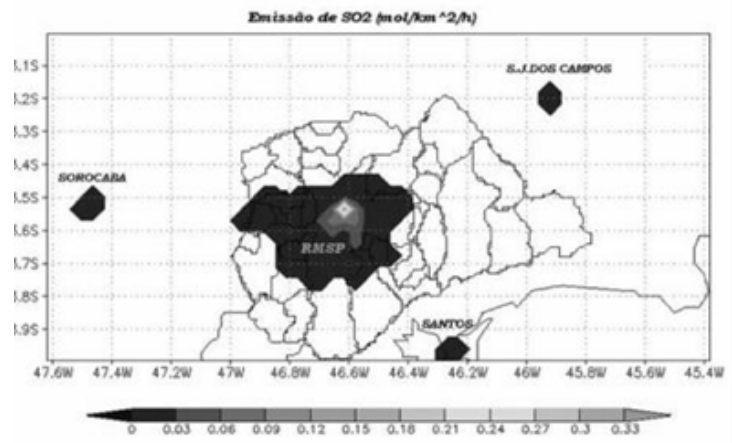

(b)

Figura 2 - (a) Detalhe das emissões de CO ( $\mathrm{kg} / \mathrm{h})$ na região central da cidade de São Paulo, com a rede viária (a espessura das tramas é proporcional ao volume de tráfego), adaptado de Landmann, 2004 e (b) Correção da distribuição espacial das emissões dos poluentes baseada na quantidade de veículos e sua velocidade média.

percentuais de emissão na RMSP (Tabela 2), ou seja, áreas com menor velocidade de tráfego implicaria em congestionamento de veículos e consequentemente maior emissão veicular.

Além da distribuição espacial, as emissões de poluentes foram trabalhadas de modo a representar as variações horárias. A Figura 3 mostra o percentual horário de emissões antropogênicas implementados nas simulações do modelo WRF/Chem para o NOx, CO, VOC. Pode-se ressaltar que a implementação feita torna o ciclo diário de emissões semelhante ao proposto por Lents et al. (2007). Para a emissão dos veículos pesados (cujo traçador é o NOx), nota-se uma distribuição temporal mais homogênea, com um máximo percentual de emissão ocorrendo às 0900 UTC. Para o ciclo de emissão dos veículos leves (tendo por referência o poluente traçador $\mathrm{CO}$ ) pode-se observar que durante o período de 1100 UTC (08:00 hora local) às 2100 UTC (18:00 hora local) não existe diminuição brusca na emissão de $\mathrm{CO}$, o que parece estar coerente com o que ocorre nas principais vias de trafego da RMSP.

Também foi proposto um novo ciclo diário para o inventário de emissão dos Compostos Orgânicos Voláteis (COV ou em inglês VOC), pois em trabalhos como o de Ynoue (2004) e mais recentemente o de Andrade (2006), foram utilizados ciclos diários de emissão fazendo apenas a distinção de veículos leves e pesados, onde o perfil diário de emissão de CO seria igual aos COV por exemplo. Pode-se observar que os perfis diários de emissão para CO e COV apresentam características bem diferentes entre os horários de 1100 - 2100 UTC.

\subsubsection{Emissões biogênicas}

O modelo trata da emissão de isoprenos, monoterpenos, outros compostos orgânicos voláteis - COV e emissão de nitrogênio pelo solo. A emissão dos isoprenos por florestas depende da temperatura e da Radiação Fotossinteticamente Ativa (RFA), que é a fração da radiação solar na faixa do visível disponível para as plantas realizarem a fotossíntese. A emissão dos monoterpenos e nitrogênio são tratados somente como função da temperatura. Resumindo, a emissão biogênica pode ser estimada de acordo com o tipo de uso do solo (cobertura do solo), que é subdividido em 24 classes de cobertura. A Tabela 3 mostra em detalhes a contribuição relativa dos diferentes tipos de vegetações como fonte de emissão biogênica de compostos atmosféricos. De acordo com Guenther et al. (2006), as emissões biogênicas liberam para a atmosfera, principalmente metano e isoprenos, sendo as atividades microbianas responsáveis por grande parte da emissão de metano e as plantas por aproximadamente $90 \%$ da emissão global dos isoprenos.

Tabela 2 - Distribuição percentual da emissão na RMSP, baseada no tráfego de veículos.

\begin{tabular}{c|c|c|c|c|c|c}
\hline Classes & \multicolumn{2}{|c|}{$\begin{array}{c}\text { - Intervalos - } \\
\text { Emissões CO }(\mathrm{kg} / \mathrm{h})\end{array}$} & $\begin{array}{c}\text { Pto. Médio } \\
(\mathrm{kg} / \mathrm{h})\end{array}$ & $\begin{array}{c}\text { Qtd. Pontos } \\
\text { de Grade }\end{array}$ & $\begin{array}{c}\text { Pto.Médio x } \\
\text { Qtd.Pto.Grade }\end{array}$ & $\begin{array}{c}\text { Distribuição } \\
\text { Percentual }\end{array}$ \\
\hline $\mathrm{F}$ & 11000 & 9000 & 10000 & 1 & 10000 & $5,62 \%$ \\
\hline $\mathrm{E}$ & 9000 & 7000 & 8000 & 4 & 32000 & $17,98 \%$ \\
\hline $\mathrm{D}$ & 7000 & 5000 & 6000 & 5 & 30000 & $16,85 \%$ \\
\hline $\mathrm{C}$ & 5000 & 3000 & 4000 & 13 & 52000 & $29,21 \%$ \\
\hline $\mathrm{B}$ & 3000 & 1000 & 2000 & 16 & 32000 & $17,98 \%$ \\
\hline $\mathrm{A}$ & 1000 & 0 & 500 & 44 & 22000 & $12,36 \%$ \\
\hline Total & & & 30500 & 83 & 178000 & $100,00 \%$ \\
\hline \hline
\end{tabular}




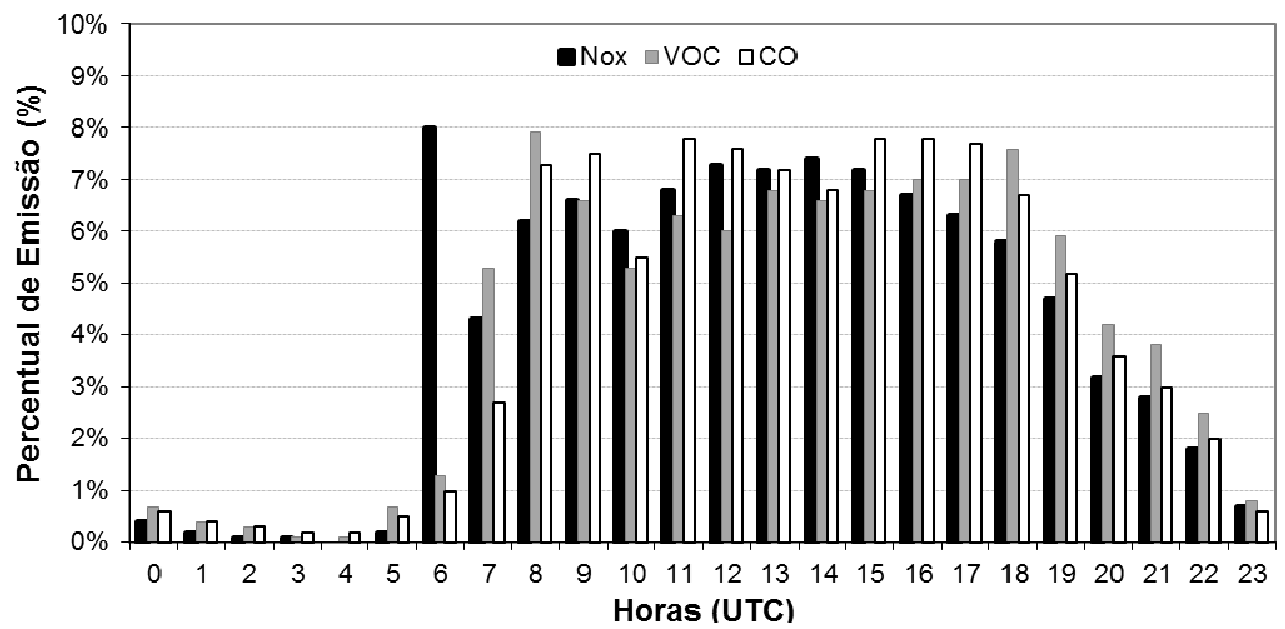

Figura 3 - Percentual horário de emissões antropogênicas para variação temporal de entrada do modelo WRF/Chem, baseada no perfil de emissões veiculares publicado pela CETESB.

Tabela 3 - Média global do fator de emissão $\varepsilon\left(\mathrm{mg}\right.$ isopreno $\left.\mathrm{m}^{-2} \cdot \mathrm{h}^{-1}\right)$, área superficial de $10^{6} \mathrm{~km}^{2}$ e contribuição percentual para a emissão de isopreno global anual e regional associada com os diferentes tipos de plantas.

\begin{tabular}{|c|c|c|c|c|c|c|c|}
\hline & & $\begin{array}{l}\text { Árvores } \\
\text { deciduais e } \\
\text { de folhas } \\
\text { verdes e } \\
\text { largas }\end{array}$ & $\begin{array}{l}\text { Árvores } \\
\text { de folhas } \\
\text { verdes e } \\
\text { finas }\end{array}$ & $\begin{array}{l}\text { Árvores } \\
\text { deciduais } \\
\text { de folhas } \\
\text { finas }\end{array}$ & Arbustos & Culturas & $\begin{array}{l}\text { Grama } \\
\text { outros }\end{array}$ \\
\hline \multirow[t]{2}{*}{ Global $\varepsilon$} & Média & 12,6 & 2,0 & 0,7 & 10,7 & 0,09 & 0,5 \\
\hline & Faixa & $0,1-30$ & $0,01-13$ & $0,01-2$ & $0,1-30$ & $0,01-1$ & $0,004-1,2$ \\
\hline \multicolumn{2}{|c|}{ Estimativa Global } & & $8,6-20,0$ & $1,3-3,9$ & $15,6-24,4$ & $8,0-36,5$ & $17,2-38,6$ \\
\hline \multirow{6}{*}{$\begin{array}{l}\text { Emissão de } \\
\text { Isopreno }\end{array}$} & Tropical & $45 \%$ & $<0,01 \%$ & $<0,01 \%$ & $28 \%$ & $0,3 \%$ & $0,6 \%$ \\
\hline & Temperada & $4,8 \%$ & $0,3 \%$ & $<0,01 \%$ & $4,5 \%$ & $<0,01 \%$ & $0,3 \%$ \\
\hline & Mediterrâneo & $0,2 \%$ & $0,1 \%$ & $<0,01 \%$ & $1,5 \%$ & $<0,01 \%$ & $<0,01 \%$ \\
\hline & Boreal/Tundra & $0,3 \%$ & $0,4 \%$ & $<0,01 \%$ & $1,0 \%$ & $<0,01 \%$ & $0,2 \%$ \\
\hline & $\begin{array}{l}\text { Superfícies } \\
\text { Áridas }\end{array}$ & $0,3 \%$ & $0,1 \%$ & $<0,01 \%$ & $11 \%$ & $<0,01 \%$ & $0,2 \%$ \\
\hline & Global & $51 \%$ & $1,1 \%$ & $<0,01 \%$ & $46 \%$ & $0,3 \%$ & $1,4 \%$ \\
\hline
\end{tabular}

De acordo com Guenther et al. (2006), as emissões biogênicas são estimadas como mostrado na Equação 1, que depende diretamente do tipo de vegetação, temperatura do ar, umidade do solo, radiação fotossinteticamente ativa, e outros.

$$
\begin{aligned}
& E M=e * g_{C E} * g_{A G E} * \gamma_{S M} * \rho \\
& g_{C E}=g_{L A I} * \gamma_{P} * \gamma_{T}
\end{aligned}
$$

Onde: $E M$ - Emissão $\left(\mathrm{mg} \cdot \mathrm{m}^{-2} \cdot \mathrm{hr}^{-1}\right), \varepsilon-$ Fator de Emissão (mg. $\left.\mathrm{m}^{-2} \cdot \mathrm{hr}^{-1}\right), \rho$ - Perda e produção devido ao dossel da planta, $\gamma_{C E}$ - Fator do dossel ("Canopy"); $\gamma_{A G E}$ - Leaf Age Factor (fator de idade da folha), $g_{S M}$ - Fator de umidade do solo, $\gamma_{L A I}$ - Fator de Índice de Área Foliar, $g_{P}$ - Fator de ativação da emissão pela radiação fotossinteticamente ativa (PPFD - photosynthetic photon flux density), $g_{T}$ - Fator de resposta à temperatura.

\subsubsection{Parametrização dos aerossóis}

Devido à ausência de informações sobre o inventário dos aerossóis, optou-se por desligar esse modulo químico do modelo e analisar somente os poluentes fotoquímicos. Em trabalhos futuros essa parametrização será incluída.

\subsubsection{Freqüuência de fotólises}

São 21 reações fotoquímicas do modelo químico da fase gás, calculadas para cada ponto de grade de acordo com Madronich (1987). A fotodissociação é a conversão da radiação solar em energia química para ativar e dissociar espécies químicas. Exemplos das espécies que são fotodissociadas são constituintes encontrados da troposfera como $\mathrm{NO}_{2}, \mathrm{O}_{3}$, 
$\mathrm{HCHO}, \mathrm{CH}_{3} \mathrm{CHO}$, $\mathrm{HONO}$, o radical $\mathrm{NO}_{3}, \mathrm{e}_{2} \mathrm{O}_{2}$. As razões de fotólises $\left(\mathrm{min}^{-1}\right)$, conhecidas também por valores $\mathrm{J}$, são computadas de acordo com a fotodissociação da reação $i$ dada por:

$$
J_{i}=\int_{\lambda_{1}}^{\lambda_{2}} F(\lambda) \sigma_{i}(\lambda) \phi_{i}(\lambda) d \lambda
$$

onde: $F(\lambda)$ é o fluxo actínico (fótons. $\left.\mathrm{cm}^{-2} \cdot \mathrm{min}^{-1} \cdot \mathrm{nm}^{-1}\right), \sigma_{i}(\lambda)$ é a secção transversal de absorção para a molécula que irá sofrer a fotodissociação $\left(\mathrm{cm}^{2}\right.$.molécula $\left.{ }^{-1}\right), \phi_{i}(\lambda)$ é o rendimento quântico da reação de fotólise (molécula.foton ${ }^{-1}$ ) e $\lambda$ é o comprimento de onda da radiação incidente $(\mathrm{nm})$. A seção transversal de absorção e o rendimento quântico são funções do comprimento de onda e podem também ser funções da temperatura e da pressão. O fluxo actínico varia com a hora do dia, latitude, longitude, altitude e estação do ano, e é governado pela relação astronômica e geométrica entre o sol e a terra.

Para o cálculo do fluxo actínico, é usado um modelo de transferência radiativa baseado na técnica do DeltaEddington estabelecida por Joseph et al. (1976). Esse modelo de transferência radiativa contabiliza a absorção de $\mathrm{O}_{2}$ e $\mathrm{O}_{3}$ através do espalhamento Rayleigh. O espalhamento e absorção por partículas de aerossóis e nuvens são descritos por Chang et al. (1989). A seção transversal de absorção e o rendimento quântico para o cálculo de $J_{\text {gás }}$ (razão de fotólise para o gás) são dados por Stockwell et al. (1990). A equação da frequência de fotólises é resolvida para 130 comprimentos de ondas em cada ponto de grade variando entre 186 a $730 \mathrm{~nm}$.

\subsection{Condição inicial e de fronteira para a química no modelo}

Como condição inicial para os constituintes químicos ("Backgroud" ou concentração de fundo) utilizou-se uma simulação mais curta de 1 dia antes do período de estudo, para servir de entrada para a simulação do período de estudo, de modo a incorporar o efeito local nos dados de entrada. A simulação para gerar os dados de entrada teve como característica utilizar o padrão adotado pelo modelo WRF/Chem, que leva em consideração uma concentração inicial com base na interpretação do tipo de uso do solo.

Para a condição de fronteira foram utilizados os resultados das simulações globais realizadas pelo modelo Max Planck Institut (MATCH-MPI - Lawrence, 1996; Silva Junior et al., 2009), de modo a tentar diminuir os problemas de borda do domínio, pois teoricamente a concentração seria zero fora do domínio, e dependendo da direção do vento, a concentração dos poluentes nas bordas poderia interferir em áreas mais próximas ao centro do domínio.

\subsection{Validação dos resultados}

Para validar as simulações feitas com o modelo WRF/ Chem, foram utilizadas duas fontes de dados: estações de monitoramento automático da CETESB e as medições feitas durante o experimento de Políticas Públicas realizado no Instituto de Astronomia, Geofísica e Ciências Atmosféricas - Universidade de São Paulo (IAG/USP). As medições feitas pela CETESB nos meses de outubro e novembro de 2006 serviram para comparações com as simulações da composição química superficial e variáveis meteorológicas da atmosfera da RMSP.

Para comprovação da precisão das simulações realizadas com o modelo WRF foram utilizados dados de quatro estações de monitoramento da CETESB, a estação de Ibirapuera (IBI), que tem por características altos níveis de concentração de $\mathrm{O}_{3} \mathrm{e}$ por apresentar uma importante variação do tipo de uso do solo (área arborizada com pequenas áreas alagadas e rodeada por áreas urbanas), a estação de Pinheiros (PIN), que está dentro de uma área altamente urbanizada e próxima de um grande corredor de veículos que é a Marginal Pinheiros, a estação do Parque Dom Pedro II (PDP) que está localizado no centro da cidade de São Paulo tendo por principal característica ser muito urbanizada e pouco arborizada, e a estação de Santo Amaro (SAM) que está inserida em uma área menos urbanizada e localizada mais ao Sul da RMSP (ver Figura 1b).

Nas estações de monitoramento da CETESB geralmente são medidos os seguintes parâmetros: Partículas Inaláveis $\left(\mathrm{MP}_{10}\right)$, dióxido de enxofre, óxidos de nitrogênio, Ozônio, monóxido de carbono, direção e velocidade do vento, umidade relativa do ar, temperatura do ar, pressão atmosférica e radiação solar (global e ultravioleta).

As análises estatísticas realizadas foram baseadas nas comparações feitas entre os resultados do modelo e observações, utilizando as formulações apresentadas na Tabela 4, para descrever a média, desvio padrão, coeficiente de correlação, erro médio ou Viés (EM), raiz do erro médio quadrático (RMSE).

\section{RESULTADOS E DISCUSSÕES}

\subsection{Descrição das condições meteorológicas}

As variações anuais da temperatura do ar, velocidade do vento e radiação solar, apresentadas na Figura 4 para o ano de 2006, mostram grande disponibilidade de radiação solar, altos valores de temperatura do ar e ventos intensos. De acordo com Pereira Filho et al. (2007), os ciclos anuais apresentados na Figura 4 são coerentes com a normal climatológica da RMSP. Vale salientar que o trimestre setembro-outubro-novembro apresenta uma combinação de disponibilidade de radiação solar 
Tabela 4 - Equações e indicadores para as analises estatísticas a serem utilizadas na validação.

\begin{tabular}{|c|c|c|}
\hline Média $(\bar{P})$ & Eq. $4 \bar{P}=\frac{1}{N} \sum_{i=1}^{N} P_{i}$ & $\begin{array}{l}\text { Valor médio do Observado e } \\
\text { Simulado/Previsto }\end{array}$ \\
\hline Desvio Padrão $(\sigma)$ & Eq. $5 \sigma=\sqrt{\frac{\sum_{i=1}^{N}\left(P_{i}-\bar{P}\right)^{2}}{N}}$ & $\begin{array}{c}\text { Variação dos dados com base na } \\
\text { média }\end{array}$ \\
\hline $\begin{array}{l}\text { Erro Médio ou } \\
\text { Viés (EM) }\end{array}$ & $E q .6 E M=\frac{1}{N} \sum_{i=1}^{N}(P i-O i)$ & $\begin{array}{c}\text { Média das diferenças, melhor } \\
\text { valores próximo a } 0\end{array}$ \\
\hline $\begin{array}{ll}\text { Coeficiente } & \text { de } \\
\text { Correlação (r) } & \end{array}$ & $E q .7 r=\frac{\sum_{i=1}^{N}\left(P_{i}-\bar{P}\right)\left(O_{i}-\bar{O}\right)}{\sqrt{\sum_{i=1}^{N}\left(P_{i}-\bar{P}\right)^{2}} \cdot \sqrt{\sum_{i=1}^{N}\left(O_{i}-\bar{O}\right)^{2}}}$ & $\begin{array}{c}\mathrm{r} \geq 0,70 \text { correlação forte } \\
0,30 \leq \mathrm{r}<0,70 \text { correlação } \\
\text { moderada } \\
\mathrm{R}<0,30 \text { correlação fraca }\end{array}$ \\
\hline $\begin{array}{llr}\text { Raiz } & \text { do } & \text { Erro } \\
\text { Médio } & \text { Quadrático } \\
\text { (RMSE) } & \end{array}$ & $E q .8 R M S E=\sqrt{\frac{1}{N}} \sum_{i=1}^{N}\left(P_{i}-O_{i}\right)^{2}$ & $\begin{array}{c}\text { Média das diferenças } \\
\text { quadráticas, melhor próximo a } 0\end{array}$ \\
\hline
\end{tabular}

Onde: " $N$ " número total de dados, " $P$ " dados simulados/previsto, " $O$ " dados Observados.
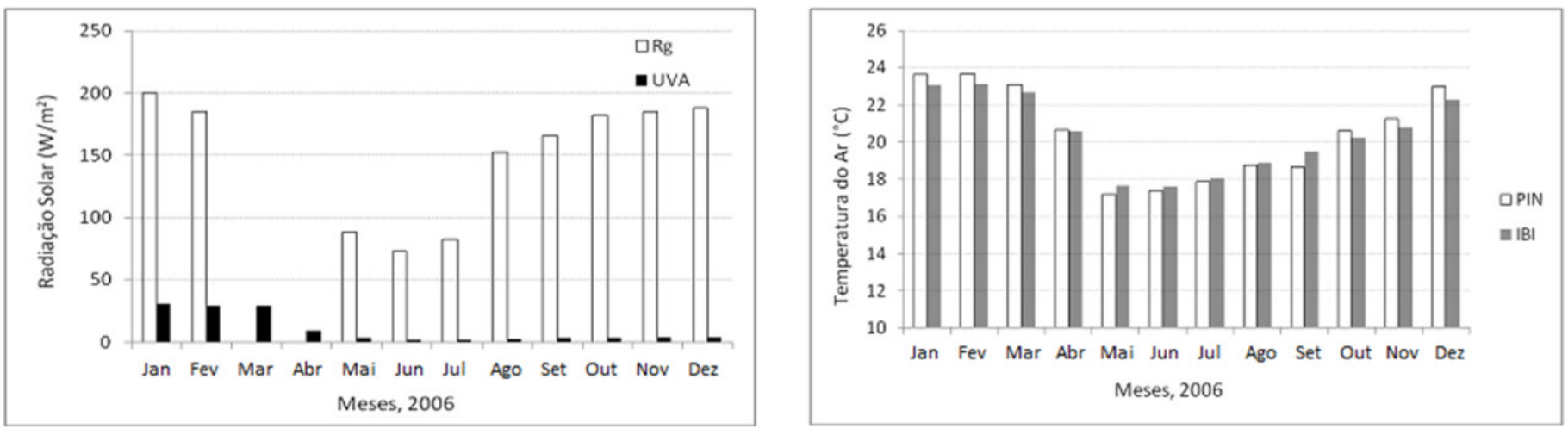

a )

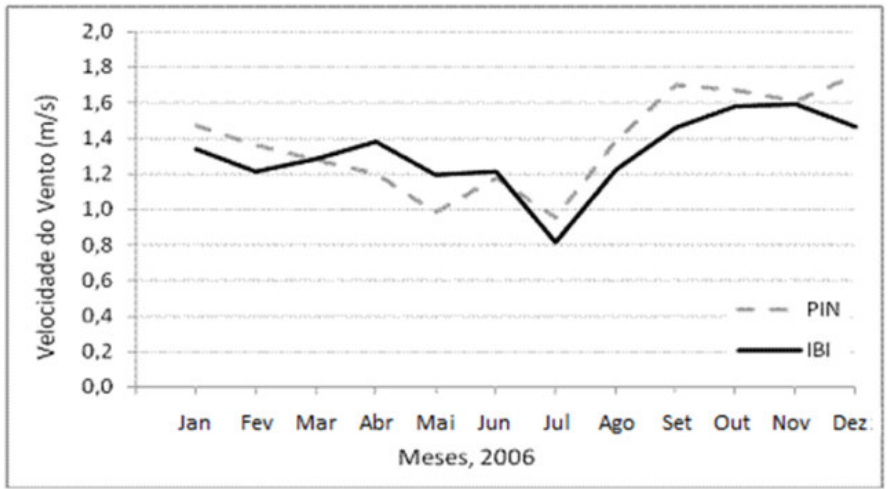

c )

Figura 4 - Ciclo anual de algumas variáveis meteorológicas, (a) para a estação de Ibirapuera (IBI) a radiação global (Rg) e Ultravioleta (400 - 320 nm, UVA), e para as estações de IBI e Pinheiros (PIN) para (b) temperatura do ar e (c) velocidade do vento, para o ano de 2006.

e baixo índice de nebulosidade, que favoreceram a ocorrência de altos valores de concentração de $\mathrm{O}_{3}$.

A principal motivação para a escolha deste período de estudo foi à ocorrência de grande número de ultrapassagens do padrão de qualidade do ar para o poluente $\mathrm{O}_{3}\left(160 \mathrm{mg} \cdot \mathrm{m}^{-3} \mathrm{ou}\right.$ 82ppb), divulgado pelo relatório anual da CETESB. De acordo com o relatório anual da CETESB (2007), o mês de outubro apresenta características favoráveis para a formação de $\mathrm{O}_{3}$, que seriam principalmente a maior disponibilidade de radiação solar (conforme pode ser observado na Figura 4). Os meses 
mais quentes como o de dezembro e janeiro apresentam uma diminuição na quantidade de episódios de altas concentrações explicados pelo aumento da nebulosidade, o que diminui a incidência de radiação solar, e consequentemente diminuição das reações fotoquímicas.

O período estudado, entre 28/10/2006 e 01/11/2006, foi caracterizado por céu claro com pouca nebulosidade sobre a RMSP, condição ideal para a formação de ozônio devido a grande disponibilidade de radiação solar. Com base na Figura 5, o período escolhido apresenta como condição meteorológica as situações de pós-frente fria e pré-frontal, o que afeta de forma efetiva os níveis de concentração de $\mathrm{O}_{3}$ (Sánchez-Ccoyllo,
2002). Outro fator importante para as altas concentrações de $\mathrm{O}_{3}$ foi a estagnação da atmosfera, pois o estudo se deu depois da passagem de uma frente fria e antes da chegada de uma nova frente fria. De acordo com Abreu (1984) a estagnação da atmosfera é uma condição que favorece altas concentrações de poluentes próximo à superfície, devido a ventos relativamente fracos em superfície e também a movimentos subsidentes em 500 $\mathrm{hPa}$. Portanto, a passagem da frente fria tornou a atmosfera mais estável, aumentando a concentração de $\mathrm{NO}$ que provavelmente fez diminuir a concentração $\mathrm{O}_{3}\left(\mathrm{NO}+\mathrm{O}_{3} \rightarrow \mathrm{NO}_{2}+\mathrm{O}_{2}\right)$. Logo analisando a intensidade do vento no período noturno do dia anterior e em seguida a concentração de $\mathrm{O}_{3}$ do dia em questão,

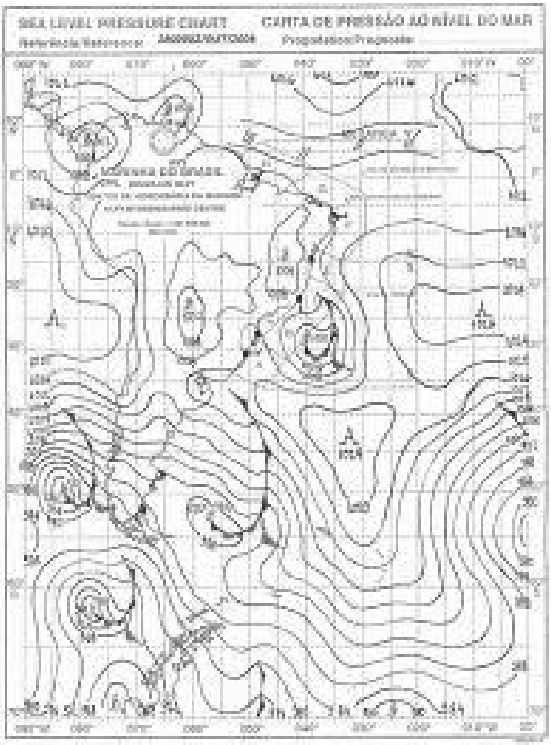

a )

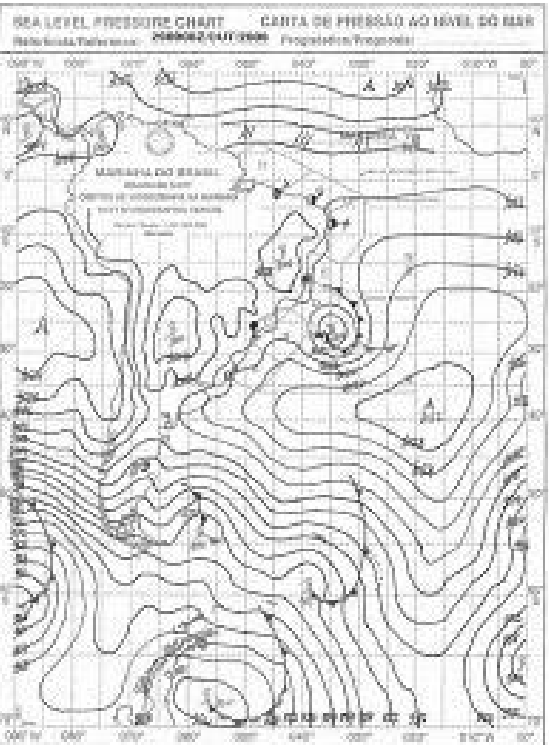

b )

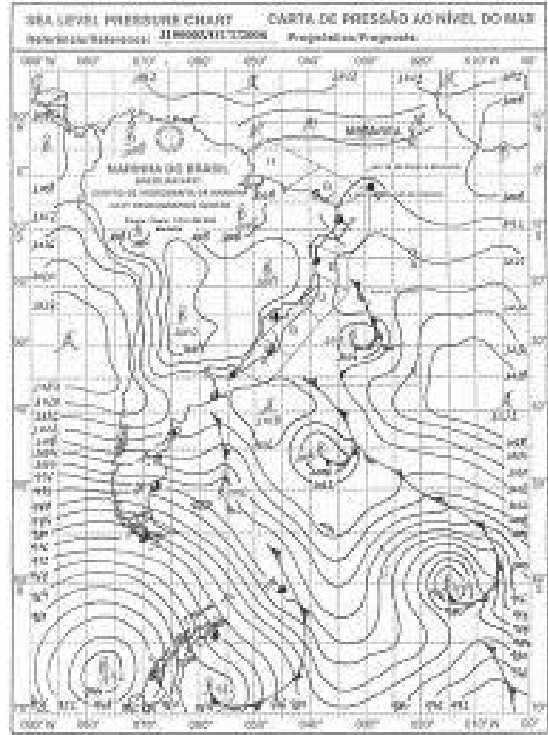

d )

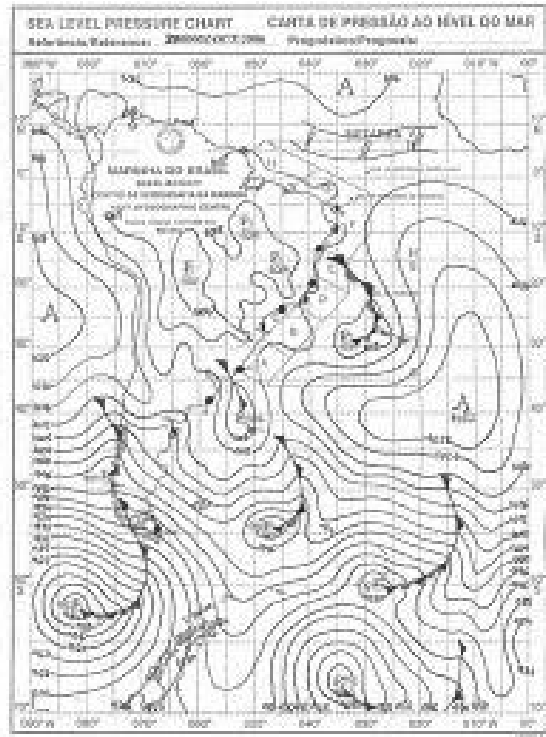

c )

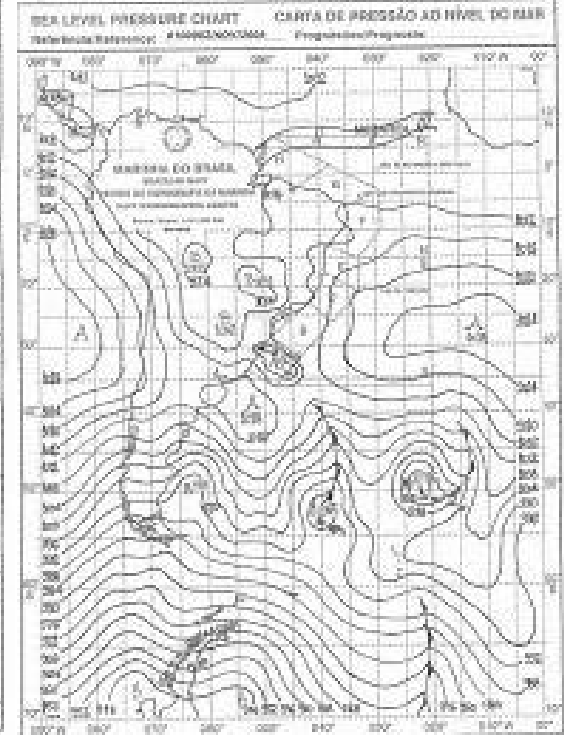

e )

Figura 5 - Análise sinóticas para 00UTC dos dias (a) 28/10/2006, (b) 29/10/2006, (c) 30/10/2006, (d) 31/10/2006 e (e) 01/11/2006. Fonte: Diretoria de Hidrologia e Navegação - DHN, 2006. 
verificou-se que existe uma relação inversamente proporcional, ou seja, um possível indicativo de altas concentrações de $\mathrm{O}_{3}$ poderia ser a intensidade do vento na noite anterior do dia considerado.

Nos dias 28 e 29/10/2006, apesar de apresentar maior disponibilidade de radiação global (Figura 7) foi registrada baixas concentrações de $\mathrm{O}_{3}$ com possível explicação para o fato que no período noturno destes dias a velocidade do vento serem maiores em comparação aos demais dias, ou seja, as máximas concentrações de $\mathrm{O}_{3}$ estaria condicionada a intensidade do vento do período noturno do dia anterior (aumento da concentração dos percussores do $\mathrm{O}_{3}$ ). Já os dias 30/10, 31/10 e 01/11/2006, a RMSP ficou entre duas frentes formando uma configuração que favoreceu a formação de ozônio, apesar da menor disponibilidade de radiação global e principalmente a ocorrência de ventos fracos durante o período noturno (ver Figuras 5, 6, e 7).
Os ventos em superfície medidos pelas estações automáticas de monitoramento da CETESB para as estações do Ibirapuera e Pinheiros são apresentados na Figura 6. Os ventos sopram de sul durante os dias 28 e 29/10, comprovando a condição pós-frontal. A atuação do sistema de baixa pressão sobre o Oceano Atlântico próximo à costa brasileira com movimentos ciclônicos (Figuras 5a e 5b) é trazer ar úmido e frio do oceano Atlântico. Já para o restante do período, nota-se também a atuação de outro sistema de baixa pressão, agora sobre o continente que é responsável pelos ventos secos e quentes vindos da direção Norte (área continental). Na Figura 8 é possível perceber ventos vindos principalmente de Norte e Sul para os dias 30, 31 e 01/11.

Com o auxílio da Figura 7 é possível notar a maior disponibilidade de radiação global nos dias 27, 28, 29 e

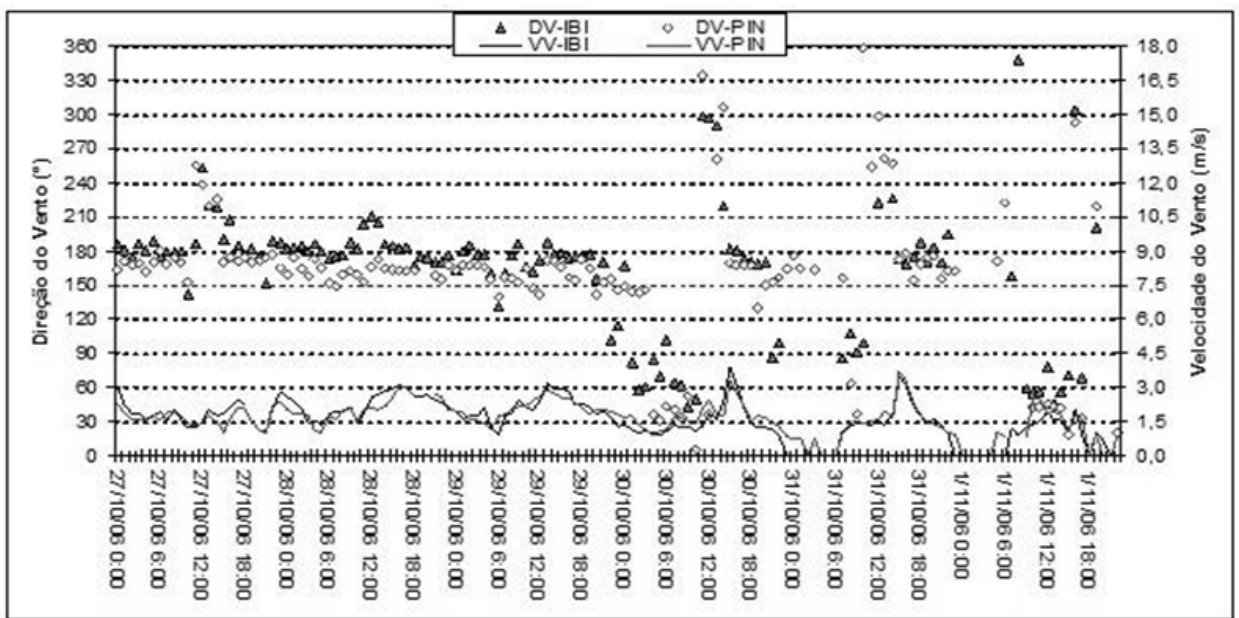

Figura 6 - Evolução temporal da velocidade (VV) e direção (DV) do vento para o período entre 27/10/2006 00h a 02/11/2006 00h hora local. Para as estações de Ibirapuera (IBI), e Pinheiros (PIN).

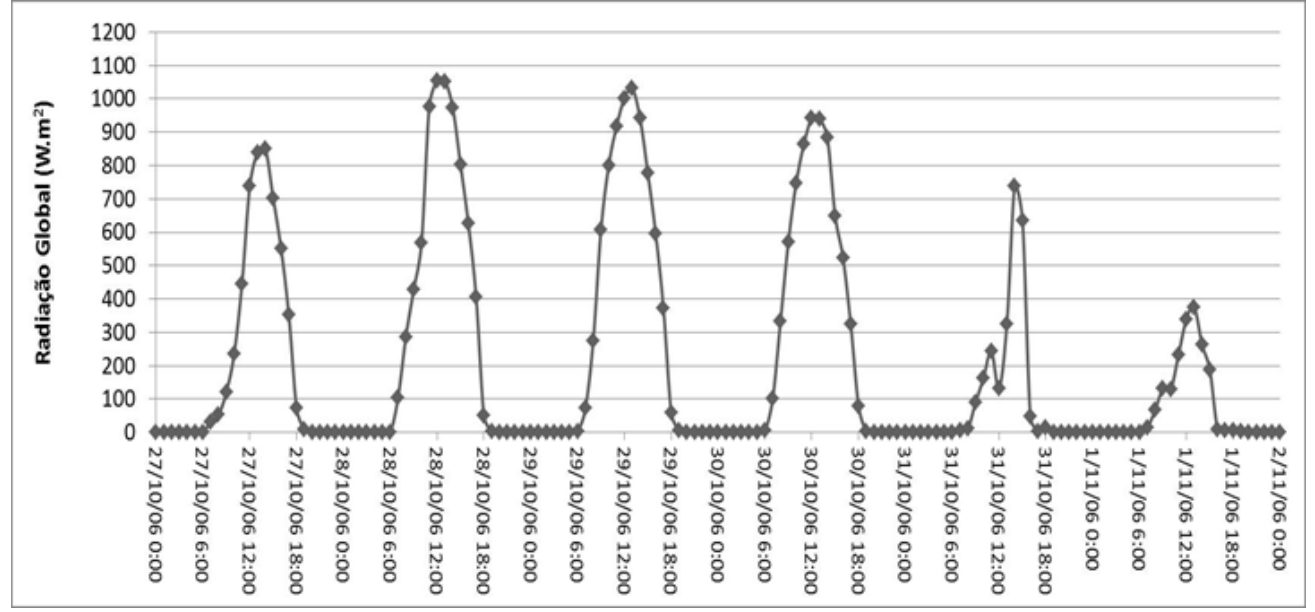

Figura 7 - Evolução temporal da Radiação Global (Rg) para o período entre 27/10/2006 00h a 02/11/2006 00h hora local. Para a estação . 
30/10/2006, e diminuição da radiação global disponível para os dias 31/10 e 01/11/2006, mas vale salientar que apesar da formação do ozônio troposférico depender da fotólise, essa não foi a principal condição para a variação da concentração de $\mathrm{O}_{3}$, e sim a intensidade do vento do período noturno do dia anterior que mostrou ser mais importante para o aumento da concentração de $\mathrm{O}_{3}$.

\subsection{Simulação com o modelo WRF/Chem}

Com base na Figura 8b é possível notar que o máximo de concentração de $\mathrm{O}_{3}$ está localizado no centro da RMSP, onde os poluentes emitidos e formados dentro da RMSP são transportados da zona urbana para a zona rural de acordo com a direção e intensidade do vento. A concentração de $\mathrm{CO}$ pode servir como indicativo do transporte de poluentes sem a forte interferência das reações químicas. Vale lembrar que em média o tempo de vida do CO na atmosfera é de aproximadamente 2 meses (Andrade, 2006 apud Jacob, 1999). Na comparação entre os períodos diurno e noturno, observa-se que ocorre pouca dispersão de poluentes em baixos níveis durante o dia, onde as máximas concentrações de $\mathrm{CO}$ são encontradas dentro da RMSP (Figura 8d), ou seja, próximo da área de emissão. Já no período da noite (2300UTC) o transporte horizontal de poluentes, associado à direção do vento de sudeste em resposta ao efeito topográfico, é na direção Noroeste da RMSP (Figura 9d). A fraca dispersão de $\mathrm{CO}$, que indica também a menor dispersão de outros poluentes, e a ausência de radiação solar propiciam uma situação favorável para o consumo de $\mathrm{O}_{3}$ acarretando em diminuição da concentração de $\mathrm{O}_{3}$ (Figura 9a). A variação da concentração e transporte de poluentes está diretamente relacionada com a direção e intensidade do vento, e o desenvolvimento da Camada Limite Planetária (CLP). Durante o dia, o maior aquecimento da superfície da RMSP do que da zona rural implica em maior desenvolvimento da CLP, o que reflete em maior transporte vertical de poluentes. Para o período noturno o efeito da topografia atua canalizando o vento na direção sudeste, transportando os poluentes para uma localidade à Noroeste da RMSP, situação que se repete para todas as noites do período de estudo.

As Figuras 8 e 9 mostram que a dispersão horizontal de poluentes em baixos níveis é mais intensa durante período noturno em comparação ao diurno, devido principalmente à diminuição do movimento convectivo ocasionado pelo resfriamento radiativo. A diminuição da concentração de $\mathrm{CO}$ durante o dia é explicada pelo maior transporte vertical e horizontal dos poluentes, e combinado ao efeito das reações químicas envolvendo os precursores de $\mathrm{O}_{3}$ e radiação solar, são mais eficientes comparativamente à reação química de consumo de $\mathrm{O}_{3}$ com o $\mathrm{NO}$. Logo com saldo positivo, a tendência é aumentar a concentração de $\mathrm{O}_{3}$. A Figura
9 c representa um fato comum para todos os dias simulados, onde para o período noturno a direção preferencial para o transporte horizontal de poluentes é de Sudeste, explicado pela direção do vento e principalmente pela topografia (ver Figura 8a), que canaliza o fluxo de ar para Noroeste da RMSP.

Para avaliar se a emissão de poluentes de cidades vizinhas interfere na qualidade do ar da RMSP, foram incluídas no domínio de simulação as emissões das cidades de São José dos Campos, Baixada Santista e Sorocaba (Figura 2b). Os resultados mostram que os poluentes emitidos em outros grandes centros urbanos próximo à RMSP não afetaram de forma significativa na composição química de sua atmosfera, mas alguns resultados mostraram um transporte de poluentes da regiões metropolitanas de São Paulo interferindo em Campinas e Sorocaba (Figura 10). O transporte de poluentes da RMSP ocorre com maior frequência no período da noite (dias 28, 29, 30 e 31/10/2006) por volta das 0100UTC, onde provavelmente estaria relacionado com o tempo que os poluentes são transportados da RMSP até a região metropolitana de Campinas. Já o transporte da RMSP para a região metropolitana de Sorocaba ocorre com menor frequência, dia 29/10/2006 às 14UTC, devido principalmente a influência da topografia e ao regime de ventos que é preferencialmente de sudeste (CETESB, 2003). A Figura $2 b$ mostra a posição da RMSP e das cidades Sorocaba, São José, Baixada Santista, e a cidade de Campinas está a Noroeste da RMSP.

\subsection{Validação das simulações em superfície}

Para validação das simulações foram utilizados os dados medidos pelas estações de monitoramento automático da CETESB. O critério utilizado para a escolha das estações considerou a disponibilidade dos dados, localização da estação e altos níveis de concentração de poluentes. As estações escolhidas foram Ibirapuera (IBI), Pinheiros (PIN), Parque Dom Pedro II (PDP) e Santo Amaro (SAM).

De modo a avaliar as simulações realizadas com o modelo $\mathrm{WRF} / \mathrm{Chem}$, foram utilizados as variáveis temperatura do ar e velocidade do vento, e para a química foram utilizadas as concentrações de $\mathrm{O}_{3}$ e CO. Estes variáveis meteorológicas e químicas serviram como indicadores da qualidade das simulações feitas com o modelo, tendo em vista que o principal interesse do trabalho foi avaliar a capacidade do modelo em representar a variabilidade das medições feitas para os poluentes fotoquímicos. A razão em avaliar-se também a concentração de CO deve-se ao fato do mesmo ser pouco reativo, portanto servindo como indicador da dispersão dos poluentes.

As Figuras 11 e 12 mostram que as simulações feitas com o modelo WRF/Chem reproduzem a variabilidade temporal das variáveis monitoradas nas estações da CETESB de Ibirapuera e Santo Amaro, respectivamente. Os valores 


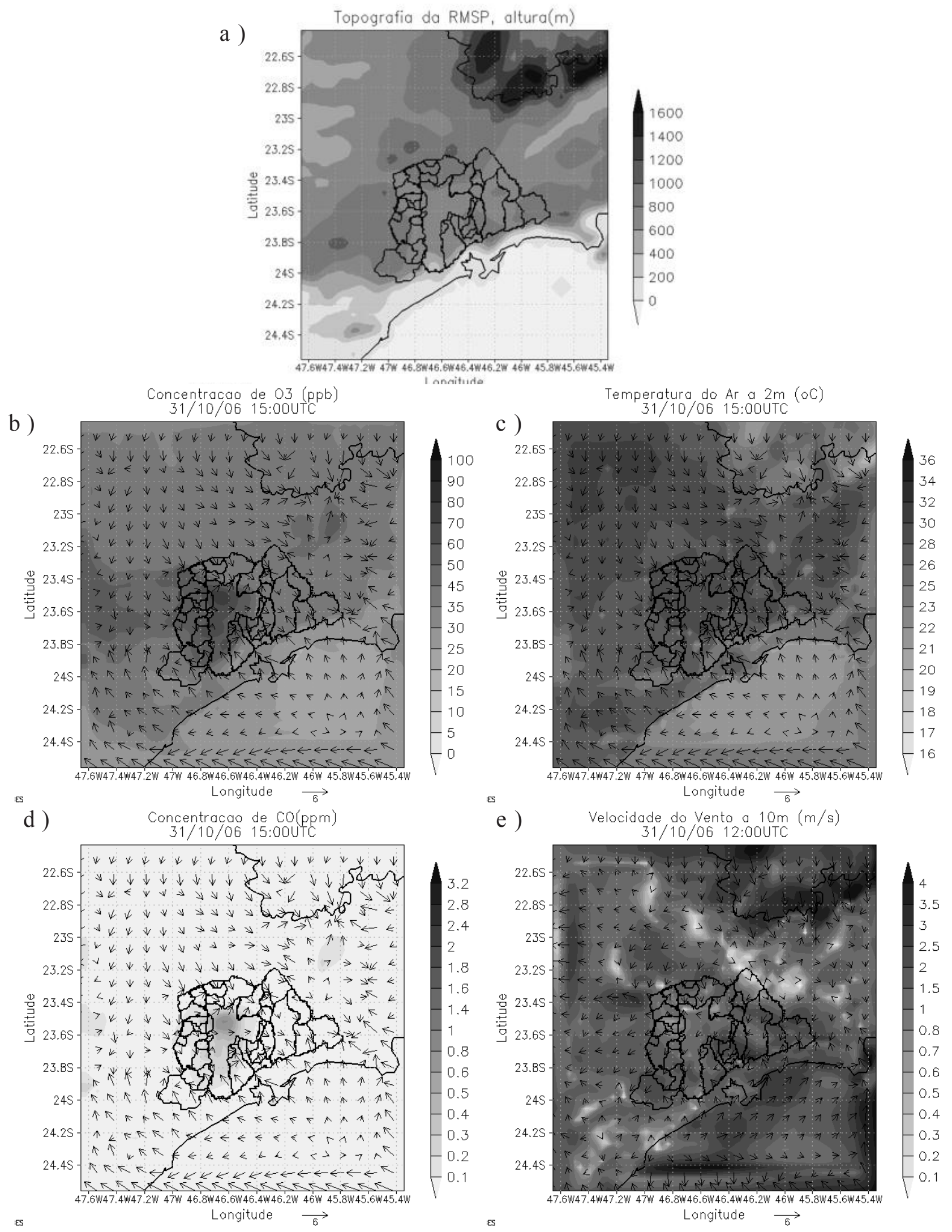

Figura 8 - (a) Topografia da área simulada, (b) simulação da concentração de $\mathrm{O}_{3}$, (c) temperatura do ar à $2 \mathrm{~m}$, (d) concentração de CO e (e) velocidade do vento à $10 \mathrm{~m}$, representando o período diurno do dia 31/10/2006. 


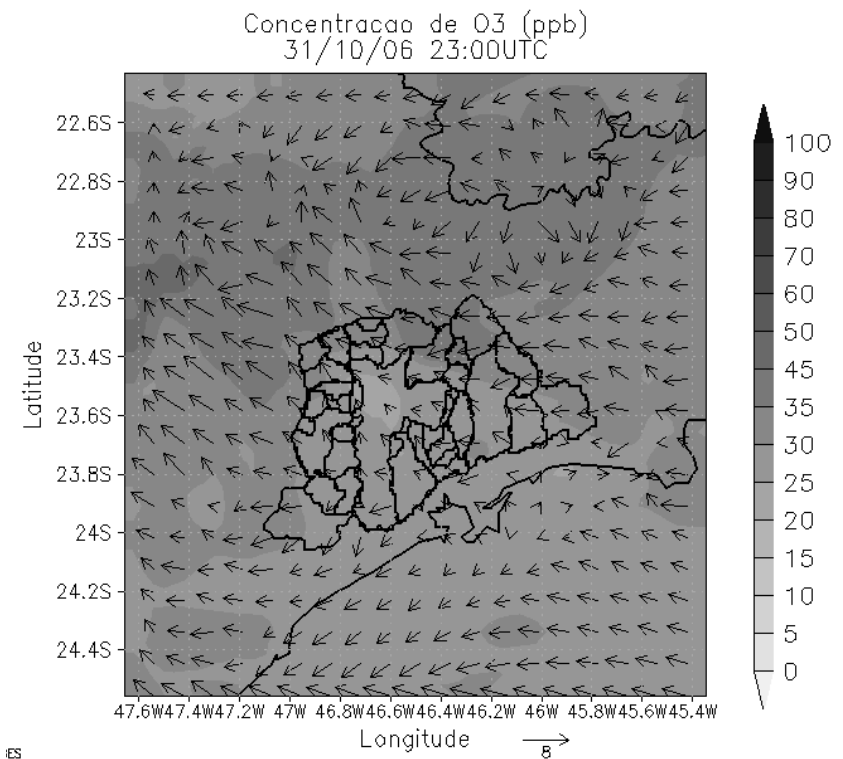

(a)

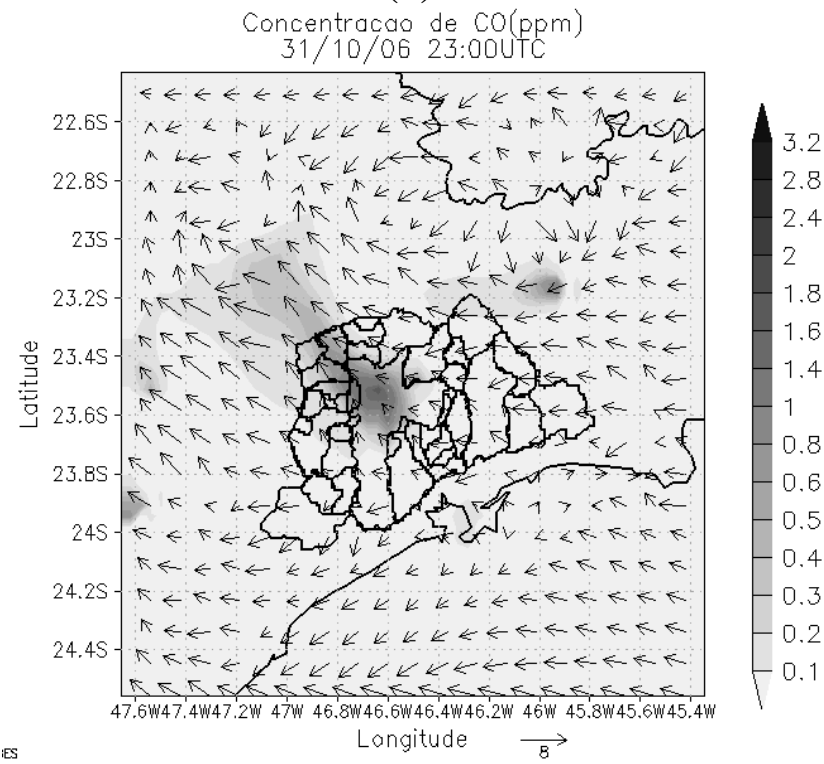

(c)

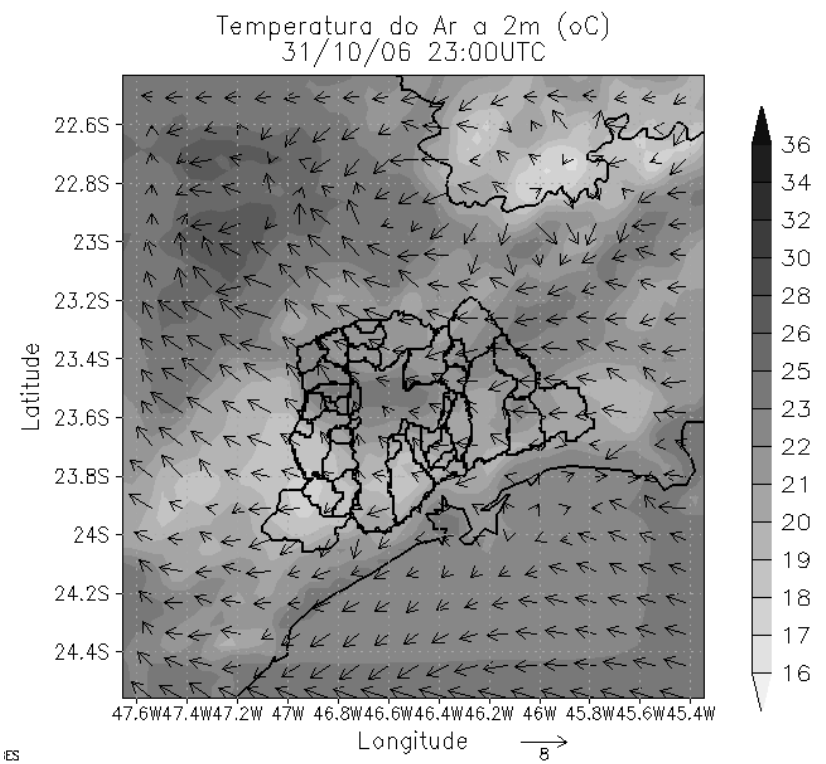

(b)

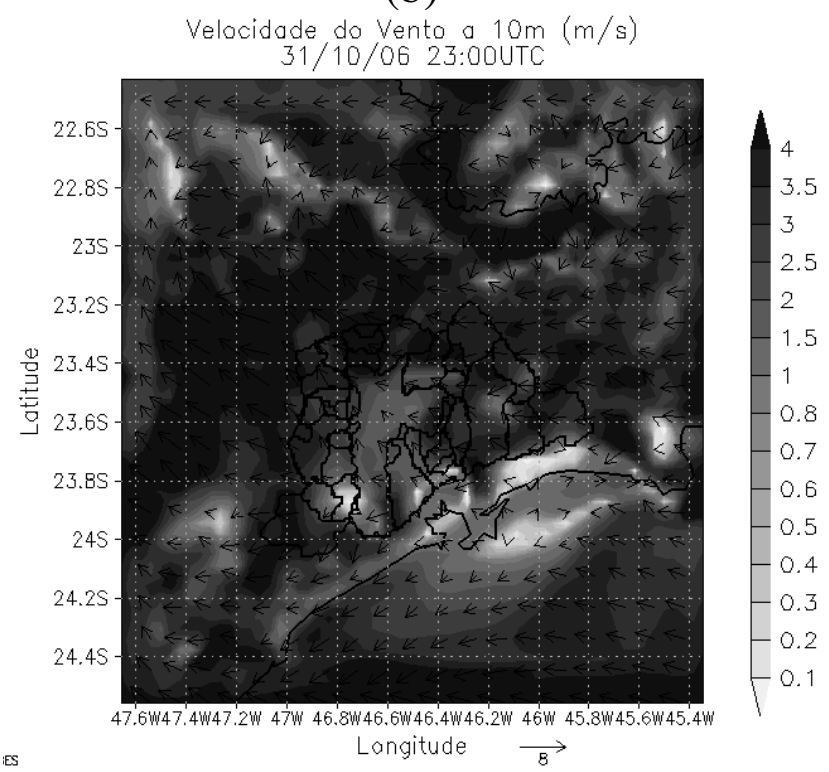

(d)

Figura 9 - (a) Simulação da concentração de $\mathrm{O}_{3}$, (b) temperatura do ar à $2 \mathrm{~m}$, (c) concentração de $\mathrm{CO}$ e (d) velocidade do vento

máximos e mínimos foram bem representados como mostram as Figuras 11 e 12 para diferentes estações de monitoramento, ou seja, o modelo conseguiu representar a fase da variabilidade temporal e espacial das variáveis, porém o valor dos picos nem sempre foram bem previstos. Esta comparação foi realizada com estações de monitoramento da qualidade do ar instaladas em locais com diferentes tipos de uso do solo: como no caso da estação de Ibirapuera, que apresenta uma cobertura superficial de lago, árvores, gramas; estação de Pinheiros que apresenta uma via de tráfego intenso e consequente grande quantidade de emissão veicular; estação do Parque Dom Pedro II que está situada no centro da grande São Paulo apresentando alto índice de urbanização e grande quantidade de veículos; a estação de Santo Amaro situada na zona sul da RMSP e apresenta uma maior variabilidade no tipo de cobertura do solo (casas, edifício, áreas arborizadas, etc). Um fator limitante que deve ser considerado é que a comparação foi feita entre medições pontuais com simulações realizadas com resolução de $5 \times 5 \mathrm{~km}$, o que interfere nas análises estatísticas.

Nas simulações realizadas para $\mathrm{O}_{3}$ e $\mathrm{CO}$ houve uma superestimativa das concentrações nas estações de Ibirapuera e Santo Amaro (Figuras 11 e 12). Mas o modelo representou a 

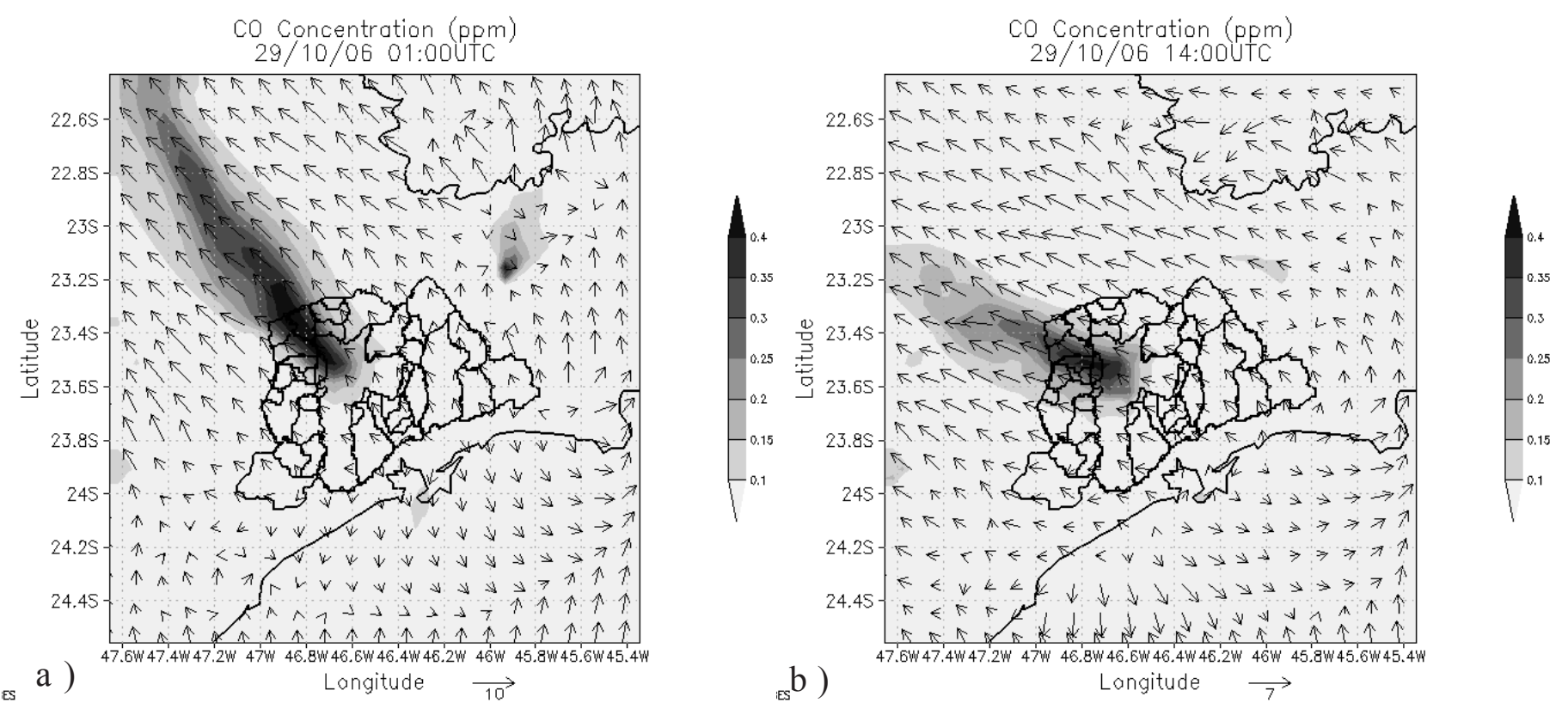

Figura 10 - (a) Exemplos de transporte de CO entre as regiões metropolitanas de São Paulo e Campinas, e (b) São Paulo e Sorocaba.

evolução temporal das condições sinóticas durante o período estudado, baixas concentrações durante os dias 28 e 29, e altas concentrações para os dias 30 e 31 . Este resultado para concentrações de $\mathrm{O}_{3}$ e $\mathrm{CO}$ pode ser atribuído à eficiência na simulação da temperatura do ar e velocidade do vento, onde as variações sinóticas e locais foram representadas pelo modelo (Figura 11). O grande problema enfrentado foi referente à configuração do perfil diário de emissão de $\mathrm{CO}$ para a estação de Ibirapuera, o que refletiu na simulação da concentração de CO mostrado na Figura 11d. Pode-se notar que a mudança do tipo de uso do solo e a distância com relação a fonte de emissão não estão sendo representadas pelo modelo em termos de emissão, pois na Figura 11d é possível observar a forte ligação entre o perfil diário de emissão com a variação diária da concentração de $\mathrm{CO}$, devido principalmente a resolução do modelo que é de $5 \times 5 \mathrm{~km}$ $\left(25 \mathrm{~km}^{2}\right)$, que seria aproximadamente 14 vezes maior do que a área do parque do Ibirapuera, que tem aproximadamente $1,3 \times 1,3 \mathrm{~km}\left(1,69 \mathrm{~km}^{2}\right)$, baseado em imagens de satélite obtida através do programa “Google Earth” em 2009. A solução para melhorar a representatividade do modelo para o caso da estação de Ibirapuera seria aumentar a resolução do modelo para $1 \times 1 \mathrm{~km}$ diferenciando melhor as áreas de emissão. Mas isso irá implicar também em melhorar a representatividade do inventário de emissão da CETESB, que atualmente tem um inventário de emissão para toda a RMSP.

Para o período de estudo as maiores concentrações de $\mathrm{O}_{3}$ ocorreram nos dias 30 e 31/10/2006 1700 UTC com valores variando de $80-100 \mathrm{ppb}$ (que é acima do padrão nacional de qualidade do ar de 80ppb). Em especial os dias 28 e 29/10/2006 foram mais frios $5^{\circ} \mathrm{C}$ em comparação aos máximos valores de temperatura do ar do restante do período estudado. Para a velocidade do vento também houve diferenças, no período noturno os ventos foram em média $1 \mathrm{~m} / \mathrm{s}$ maiores nos dias 28 e 29 , e menores em média $0,5 \mathrm{~m} / \mathrm{s}$ durante o período diurno.

Outra estação de monitoramento incluída nas análises estatísticas foi a de Santo Amaro (Figura 12), que apresentou uma variabilidade ainda maior nas concentrações de poluentes para o período estudado, certamente influenciado pela localização e tipo de cobertura superficial. O modelo também representou com sucesso a baixa concentração de $\mathrm{O}_{3}$ e CO para os dias 28 e 29 de outubro, e altas concentrações registradas para os dias 30 e 31 de outubro, em resposta à ação da condição sinótica, confirmando a hipótese levantada por Sanchez-Ccyollo (2002). Outra característica positiva apresentada pelas simulações foi a boa representação da variabilidade da velocidade do vento também para a estação de Santo Amaro. Infelizmente, nessa estação, não havia dados observados de temperatura do ar, o que reforça a importância da utilização de modelos atmosféricos acoplados com química para fazer o monitoramento da qualidade do ar e variáveis meteorológicas.

Os dias 28 e 29/10/2006 foram dias de final de semana, onde teoricamente o tráfego veicular é menos intenso e conseqüentemente as emissões veiculares também foram menores. De acordo com Silva Junior et al. (2009), a RMSP apresentou o efeito de ocorrência de concentrações mais elevadas no final de semana para o $\mathrm{O}_{3}$ em comparação ao período da semana (vale salientar que o estudo foi realizado com médias, o que provavelmente minimizou o efeito meteorológico local e sinótico sobre a composição química 

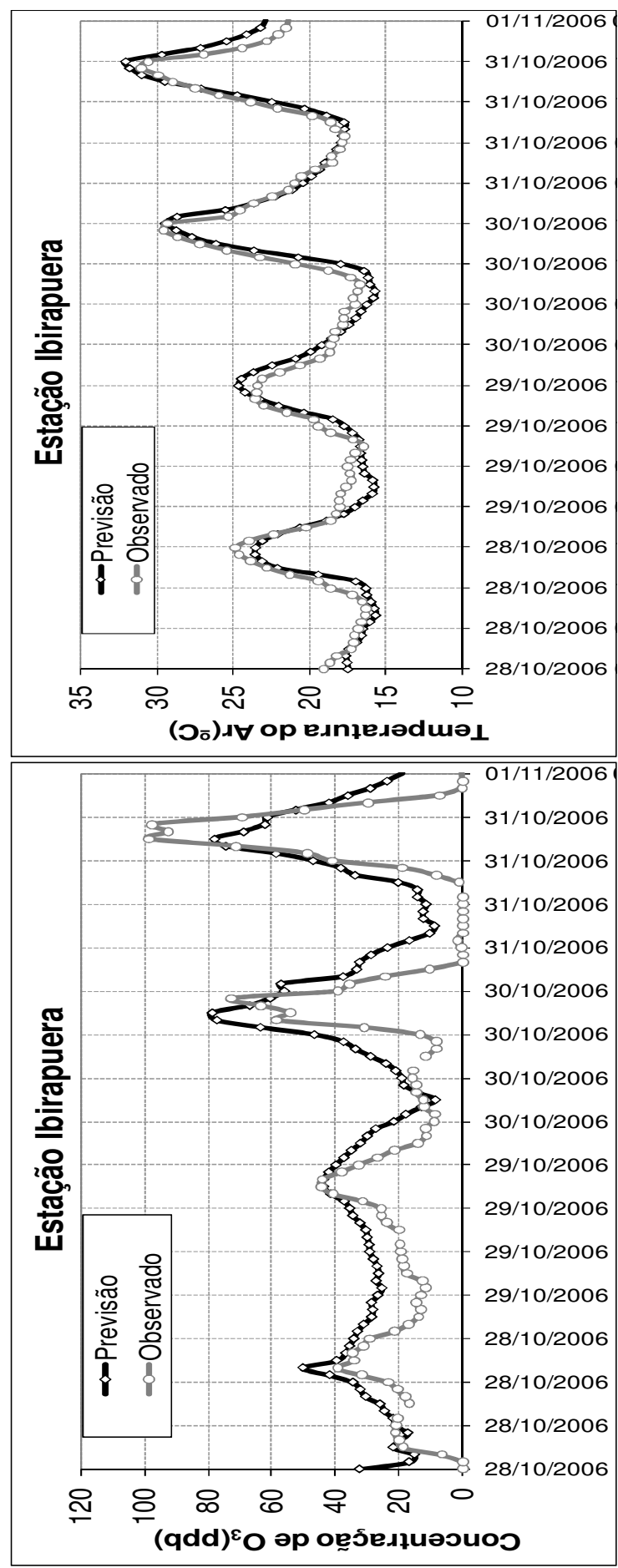
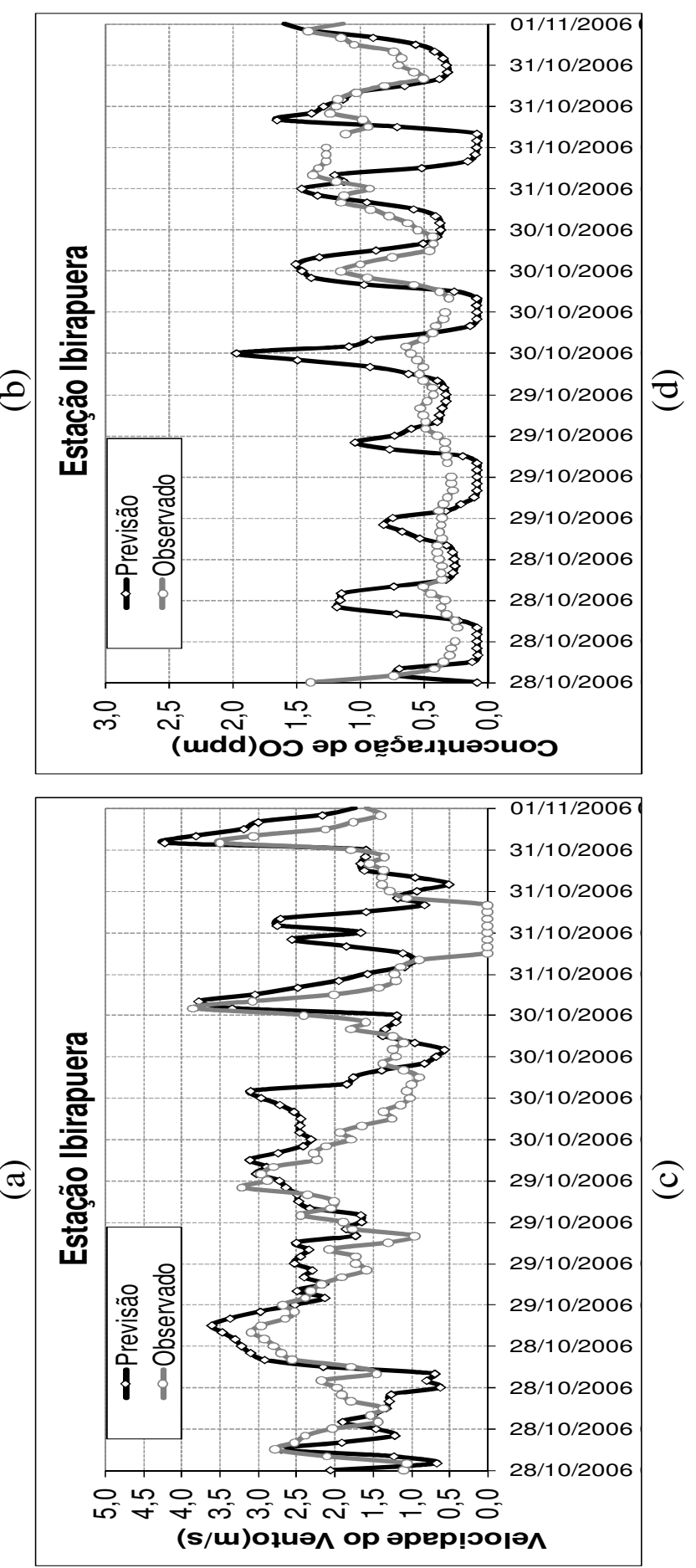

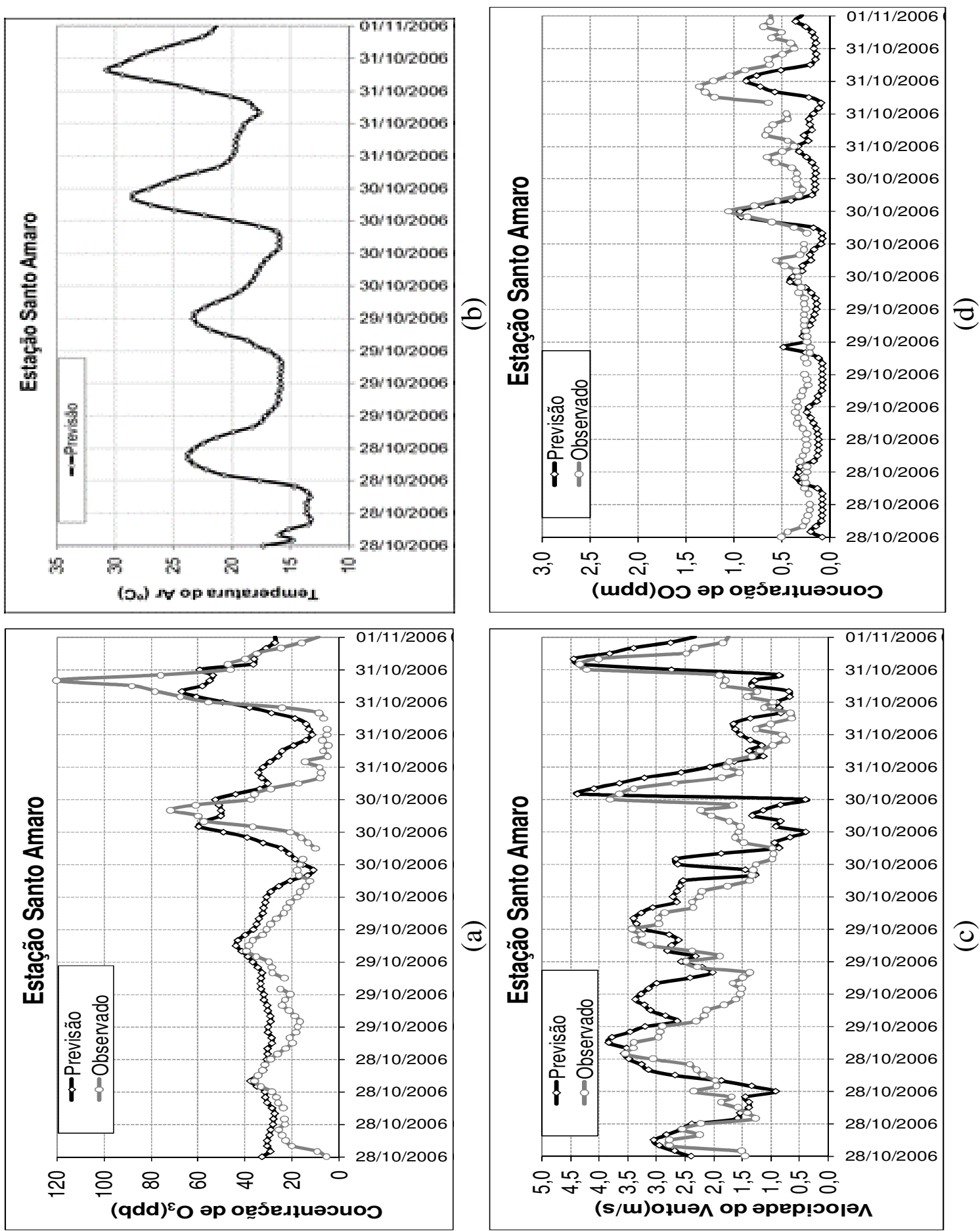
Tabela 5 - Índices estatísticos para o período de 28/10 a 01/11/2006 para as estações: Pinheiros (PIN), Ibirapuera.

\begin{tabular}{l|l|c|c|c|c|c|c|c}
\hline Variável & Estação & MS & MO & DPS & DPO & RMSE & Viés & CORR \\
\hline $\begin{array}{l}\text { Concentração } \\
\text { de } \mathrm{O}_{3}(\mathrm{ppb})\end{array}$ & PIN & 33,84 & 19,52 & 15,73 & 17,52 & 18,08 & $-14,32$ & 0,78 \\
\cline { 2 - 10 } & IBI & 34,12 & 23,55 & 16,32 & 21,6 & 15,63 & $-10,57$ & 0,85 \\
\cline { 2 - 10 } & PDP & 36,04 & 23,86 & 14,57 & 17,54 & 16,01 & $-12,18$ & 0,80 \\
\cline { 2 - 10 } & SAM & 33,98 & 28,01 & 11,21 & 19,44 & 13,84 & $-5,96$ & 0,80 \\
\hline \multirow{2}{*}{$\begin{array}{l}\text { Temperatura } \\
\text { do Ar }\left({ }^{\circ} \mathrm{C}\right)\end{array}$} & PIN & 20,44 & 21,78 & 4,41 & 5,33 & 2,04 & 1,34 & 0,97 \\
\cline { 2 - 10 } & IBI & 20,46 & 20,77 & 4,31 & 3,8 & 1,26 & 0,31 & 0,96 \\
\cline { 2 - 10 } & PDP & - & - & - & - & - & - & - \\
\cline { 2 - 9 } & SAM & - & - & - & - & - & - & - \\
\hline \multirow{2}{*}{$\begin{array}{l}\text { Velocidade do } \\
\text { Vento }(\mathrm{m} / \mathrm{s})\end{array}$} & PIN & 2,26 & 1,78 & 0,86 & 0,7 & 0,95 & $-0,48$ & 0,45 \\
\cline { 2 - 9 } & IBI & 2,09 & 1,74 & 0,86 & 0,83 & 0,9 & $-0,35$ & 0,45 \\
\cline { 2 - 9 } & PDP & - & - & - & - & - & - & - \\
\cline { 2 - 9 } & SAM & 2,3 & 2,07 & 1,03 & 0,84 & 0,84 & $-0,23$ & 0,64 \\
\hline \multirow{2}{*}{$\begin{array}{c}\text { Concentração } \\
\text { de CO (ppm) }\end{array}$} & PIN & 0,53 & 0,79 & 0,42 & 0,43 & 0,46 & 0,26 & 0,59 \\
\cline { 2 - 9 } & IBI & 0,62 & 0,64 & 0,47 & 0,34 & 0,45 & 0,02 & 0,43 \\
\cline { 2 - 9 } & PDP & 0,44 & 0,78 & 0,33 & 0,4 & 0,52 & 0,35 & 0,44 \\
\cline { 2 - 8 } & SAM & 0,25 & 0,43 & 0,19 & 0,26 & 0,26 & 0,19 & 0,70 \\
\hline
\end{tabular}

(IBI), Parque Dom Pedro II (PDP), Santo Amaro (SAM).

Obs.: MS à Média do Simulado, MO à Média do Observado, DPS à Desvio Padrão do Simulado, DPO à Desvio Padrão do Observado, RMSE à Raiz do Erro Médio Quadrático, BIAS à MO - MS, CORR à Coeficiente de Correlação entre simulação e observação.

da atmosfera). Para o presente estudo os resultados mostraram que os efeitos locais e sinóticos foram de grande importância para as simulações realizadas para a RMSP, já que não foram consideradas variações diárias das emissões durante $\mathrm{o}$ período de estudo, ou seja, a variabilidade da concentração dos poluentes químicos foi afetada somente pela condição meteorológica, tendo as emissões um papel importante para limitar os níveis de concentração.

A Tabela 5 mostra a boa correlação entre as simulações e as observações feitas para a RMSP, temperatura do ar: 0,97 para a estação de Pinheiros e 0,96 para a estação de Ibirapuera, para a concentração de $\mathrm{O}_{3}: 0,85$ para a estação de Ibirapuera e 0,80 para a estação de Santo Amaro. O modelo apresentou grandes dificuldades em simular a velocidade do vento durante $\mathrm{o}$ período noturno (ver Figuras 11c e 12c), o que pode ser atribuído a resolução da topografia e descrição do uso do solo por parte do modelo, outro detalhe que pode ter influenciado na precisão das simulações seria a forma de comparação entre simulado e observado (comparando área com ponto). A baixa precisão na simulação da velocidade do vento possivelmente deve ter influenciado na representação da concentração do $\mathrm{O}_{3}$ e CO. Zhang et al (2009) utilizando também o modelo WRF/Chem para a cidade do México sem o acoplamento urbano, também discutiram a dificuldade em simular o campo de vento no período noturno. Uma possível solução para este problema seria a utilização do acoplamento com o modelo urbano para simular os efeitos térmicos e aerodinâmicos de uma cidade. Já para a temperatura do ar, o modelo apresentou bons resultados com correlação acima de 0,96 para as estações de Ibirapuera e Pinheiros, o que contribuiu positivamente na simulação da concentração de $\mathrm{O}_{3}$ e $\mathrm{CO}$

\section{CONCLUSÕES}

O período para realizar este estudo foi escolhido porque apresentou grandes variações nas condições meteorológicas e na química da atmosfera, devido principalmente à situação sinótica. O modelo WRF/Chem foi testado em situações de extremos de máximo e mínimo valor das variáveis, conseguindo representar a variação no período de estudo e ciclos diários. Por exemplo, os dias 28 e 29/10/2006 foram marcados por baixas concentrações de $\mathrm{CO}_{\text {e }} \mathrm{O}_{3}$, e os dias 30 e 31/10/2006 com altas concentrações desses poluentes, e essa variação foi representada pelo modelo WRF/Chem mostrando sua sensibilidade a variações de meteorológicas na mesoescala.

Outro teste bem sucedido em termo de variações locais da concentração de $\mathrm{CO}$ e $\mathrm{O}_{3}$ referente à variação espacial e 
temporal das concentrações dentro da RMSP. O modelo foi capaz de reproduzir as variações das concentrações em escala local, quando comparados pontos dentro da RMSP com base nas estações de qualidade do ar da CETESB (Ibirapuera, Santo Amaro, Parque D. Pedro, Pinheiros). A dificuldade em simular os máximos e mínimos valores pode ser diminuída com a melhor descrição dos processos de superfície e do tipo de uso do solo, que estaria associado com a variação local dos processos meteorológicos (exemplo temperatura do ar e velocidade e direção do vento) e químicos (exemplo concentrações de $\mathrm{CO}$ e $\mathrm{O}_{3}$ ).

No presente trabalho foi mostrado o transporte de poluentes existente entre as regiões metropolitanas de São Paulo, Campinas, São José dos Campos e Sorocaba, devido principalmente à topografia que atua canalizando o vento na direção de Campinas e Sorocaba, ou ainda através do Vale do Paraíba que direciona o transporte de poluentes na direção de São José dos Campos. A proximidade com as fontes de emissão mostrou ser um fator importante para o nível de concentração de $\mathrm{O}_{3}$, pois à medida que se afasta das fontes de emissão, tanto vertical quanto horizontalmente, a concentração de $\mathrm{O}_{3}$ aumenta. E devido a sua relativa proximidade com o Oceano Atlântico, a RMSP é beneficiada com a formação da Brisa Marítima que auxilia na dispersão dos poluentes emitidos e formados na RMSP.

\section{REFERÊNCIAS BIBLIOGRÁFICAS}

ABREU, M. L. Previsores sinótico-meteorológicos para a dispersão de poluentes na região da grande São Paulo. Dissertação (Mestrado em Meteorologia) - INPE, São José dos Campos/SP, 1984.

ANDRADE, M. F. Caracterização das Fontes de Material Particulado e Ozônio Troposféricos na Região Metropolitana de São Paulo. Tese (Livre Docência em Metetorologia) - IAG/USP, São Paulo/SP, 2006.

ANDRADE, M. F., YNOUE, R. Y., HARLEY, R., MIGUEL, A. H. Air-Quality Model simulating photochemical formation of pollutants: the São Paulo Metropolitan Area, Brazil. International Journal Environment and Pollution, Inglaterra, v. 22, n. 4, p. 460-475, 2004.

BRAGA, A.; PEREIRA, L. A. A.; SALDIVA, P. H. N. Poluição atmosférica e seus efeitos na saúde humana. Trabalho apresentado no evento Sustentabilidade na Geração e uso de Energia, UNICAMP, 18 a 20 de fevereiro de 2002 (http:// libdigi.unicamp.br/document/?code=1039).

CARTER, W. P. L. Documentation of the saprc-99 chemical mechanism for VOC reactivity assessment volume 1 of 2 documentation text Final Report to California Air Resources Board. Air Pollution Research Center and
College of Engineering Center for Environmental Research and Technology University of California, Riverside (Contract 92-329 and Contract 95-308 9252100-AP-RT17001-FR) http://helium.ucr.edu/ carter/reactdat.htm, 2000.

CASTANHO, A.D.A. A Determinação Quantitativa de Fontes de Material Particulado na Atmosfera da Cidade de São Paulo. Dissertação (Mestrado em Física) - IF/USP, São Paulo, 1999.

CASTANHO, A.D.A. Propriedade ópticas das partículas de aerossol e uma nova metodologia para a obtenção da espessura óptica via satélite sobre São Paulo. Tese (Doutorado em Física) - IF/USP, São Paulo/SP, 2005.

CETESB Análise dos padrões de vento e de sua influência sobre as máximas concentrações de ozônio na estação Ibirapuera. http://www.cetesb.sp.gov.br/publicacoes/ publicacoes.asp, acessado em 17/07/2009, 2003.

CETESB Relatório Anual de Qualidade do Ar no Estado de São Paulo 2004. CETESB-Companhia de Tecnologia de Saneamento Ambiental, 2005, São Paulo, Brazil, 2005.

CETESB Relatório de qualidade do ar no Estado de São Paulo 2005. Série Relatórios/Secretaria do Estado do Meio Ambiente, São Paulo, 140p. (ISSN 0103-4103), 2006.

CETESB Relatório de qualidade do ar no Estado de São Paulo 2006. Série Relatórios/Secretaria do Estado do Meio Ambiente, São Paulo, 294p. (ISSN 0103-4103), 2007.

CETESB Relatório de qualidade do ar no Estado de São Paulo 2011. Série Relatórios/Secretaria do Estado do Meio Ambiente, São Paulo, 294p. (ISSN 0103-4103), 2012.

CHANG, J.S., BINKOWSKI, F.S., SEAMAN, N.L., MCHENRY, J.N., SAMSON, P.J., STOCKWELL, W.R., WALCEK, C.J., MADRONICH, S., MIDDLETON, P.B., PLEIM, J.E., LANSFORD, H.H. The regional acid deposition model and engineering model. State-of-Science/Technology, Report 4, National Acid Precipitation Assessment Program, Washington, DC, 1989.

DHN Diretoria de Hidrologia e Navegação - DHN. imagens de cartas sinóticas https://www.mar.mil.br/dhn/dhn/index. html, acesso 19/06/2012, 2006.

DUDHIA, J. Numerical study of convection observed during the winter monsoon experiment using a mesoscale twodimensional model. Journal of the Atmospheric Sciences, 46, 3077-3107, 1989.

GRELL, G.A., EMEIS, S., STOCKWELL, W.R., SCHOENEMEYER, T., FORKEL, R., MICHALAKES, J., KNOCHE, R., SEIDL, W. Application of a multiscale, coupled MM5/chemistry model to the complex terrain of the VOTALP valley campaign. Atmospheric Environment 34, 1435-1453, 2000.

GRELL, G. A., PECKHAM, S.E., SCHMITZ, R., MCKEEN, S.A., WILCZAK, J. AND EDER, B. Fully coupled 
online chemistry within the WRF model. Atmospheric Environment; vol.39; pp. 6957-6975; 2005.

GUENTHER, A., KARL. T., HARLEY, P., WIEDINMYER, C., PALMER, P. I., GERON, C. Estimates of global terrestrial isoprene emissions using MEGAN (Model of Emissions of Gases and Aerosols from Nature). Atmospheric Chemistry and Physics, 6, 3181-3210, 2006.

JACOB, D. Introduction to Atmospheric Chemistry. Princeton University Press, 1999.

JOSEPH, J. H., WISCOMBE, W.J. AND WEINMAN, J.A. The deltaEddington approximation for radiative flux transfer. Journal of the Atmospheric Sciences, 33, 2452-2459, 1976.

LAWRENCE, M. G. Photochemistry in the tropical pacific troposphere: Studies with a global 3D chemistrymeteorology model, $\mathrm{PhD}$ thesis, Georgia Institute of Technology, 520 pp., 1996.

LANDMANN, M.C. Estimativa das Emissões de Poluentes de Automóveis na RMSP Considerando as Rotas de Tráfego. II Encontro da ANPPAS, São Paulo, Brasil, 2004 [http:www.anppas.org.br/encontro/segundo/Papers/papers. html . 22/06/05].

LENTS, J; OSSES, M; NIKKILA, N. Vehicle activity and on-road emissions data collection for the application of the International Vehicle Emissions Model (IVE) in the São Paulo Metropolitan Region. Reunião de Poluição Atmosférica-IAG/USP; Maio de 2007; São Paulo - Brasil, 2007.

LIN, Y.L., FARLEY, R.D. AND ORVILLE, H.D. Bulk parameterization of the snow field in a cloud model. Journal of Climate and Applied Meteorology, 22, 1065-1092, 1983.

MADRONICH, S. Photodissociation in the atmosphere, 1, actinic flux and the effects of ground reflections and clouds. Journal of Geophysical Research, 92, 9740-9752, 1987.

MARTINS, L.D.: Sensibilidade da formação do ozônio troposférico às emissões veiculares na Região Metropolitana de São Paulo. Tese (Doutorado em Ciências Atmosféricas) - IAG/USP, São Paulo, 2006.

PEREIRA FILHO, A.J.; SANTOS, P.M.; CAMARGO, R.; FESTA, M. e outros. Impacto antrópicos no clima da Região Metropolitana de São Paulo. Boletim SBMET, abril/2007.
SALDIVA P. H. N., POPE C. A., SCHWARTZ J., DOCKERY D. W., LICHTENFELS A. J., SALGE J. M., BARONE L., BOHM G. M. Air pollution and mortality in elderly people: a timeseries study in São Paulo, Brazil. Arch. Environmental Health vol. 50, 159-163, 1995.

SANCHEZ-CCOYLLO, O. R.: Identificação da contribuição das fontes locais e remotas de poluentes na Região Metropolitana de São Paulo. Tese (Doutorado em Ciências Atmosféricas) - IAG-USP, São Paulo/SP, 2002.

SANCHEZ-CCOYLLO, O.R., YNOUE, R.Y, MARTINS, L.D., ANDRADE, M.F. Impacts of Ozone Precursor Limitation and Meteorological Variables on Ozone Concentration in São Paulo, Brazil. Atmospheric Environment, 40 (2), pp. 552-562, 2006.

SILVA JUNIOR, R.S., OLIVEIRA, M.G.L., ANDRADE, M.F. Weekend/Weekday Differences in Concentrations of Ozone, NOx, and Non-Methane Hydrocarbon in the Metropolitan Area of São Paulo. Revista Brasileira de Meteorologia, Vol. 24, n.1, 2009.

SKAMAROCK, W. C.; KLEMP, J.B.; DUDHIA, J.; GILL, D.O. BARKER, D.M.; WANG, W. POWERS, J.G. A Description of the Advanced Research WRF Version 2. NCAR Technical Note, 2005.

STOCKWELL, W.R.; MIDDLETON, P.; CHANG, J.S.; TANG,

$\mathrm{X}$. The second-generation regional acid deposition model chemical mechanism for regional air quality modeling. Journal of Geophysical Research, 95, pp. 16343-16367, 1990.

YNOUE, R. Modelagem Numérica da Formação, Crescimento e Transporte das Partículas Inorgânicas Secundárias Constituintes do Aerossol Urbano na Região Metropolitana de São Paulo. Tese (Doutorado em Ciências Atmosféricas) - IAG/USP, São Paulo/SP, 2004.

ZHANG, Y.; DUBEY, M.K. E OLSEN, S.C. Comparisons of WRF/Chem simulations in Mexico City with ground-based RAMA measurements during the MILAGRO-2006 period. Atmospheric Chemistry and Physics Discussion Journal, vol. 9, pp. 1329-1377, 2009. 